\title{
Saponin Interactions with Model Membrane Systems - Langmuir Monolayer Studies, Hemolysis and Formation of ISCOMs
}

Authors

Affiliation
Carolin de Groot, Christel C. Müller-Goymann

Institut für Pharmazeutische Technologie, Technische Universität Braunschweig, Braunschweig, Germany
Key words

- saponins

- isoprenoids

- hemolytic activity

- ISCOM

- Langmuir film balance

received April 5, 2016

revised Sept. 22, 2016

accepted Sept. 24, 2016

Bibliography

DOI http://dx.doi.org/

10.1055/s-0042-118387

Published online October 19,

2016

Planta Med 2016; 82:

1496-1512 ๑ Georg Thieme Verlag KG Stuttgart · New York . ISSN 0032-0943

Correspondence

Prof. Dr. Christel C. MüllerGoymann

Institut für Pharmazeutische

Technologie

Technische Universität

Braunschweig

Mendelssohnstraße 1

38106 Braunschweig

Germany

Phone: + 495313915650

Fax: + 495313918108

c.mueller-goymann@

tu-braunschweig.de

\section{Abstract \\ $\checkmark$}

Saponins are used in medicine due to their pharmacological and immunological effects. To better understand interactions of saponins with model membranes and natural membranes of, for example, erythrocytes, Langmuir film balance experiments are well established. For most saponins, a strong interaction with cholesterol was demonstrated in dependence of both the aglycone part and the sugar moieties and is suggested to be correlated with a strong hemolytic activity, high toxicity, and high surface activity, as was demonstrated for the steroid saponin digitonin. In general, changes in the sugar chain or in substituents of the aglycone result in a modification of the saponin properties. A promising saponin with regard to fairly low hemolytic activity and high adjuvant effect is $\alpha$-tomatine, which still shows a high affinity for cholesterol. An interaction with cholesterol and lipids has also been proven for the Quillaja saponin from the bark of Quillaja saponaria Molina. This triterpene saponin was approved in marketed vaccines as an adjuvant due to the formation of immunostimulating complexes. Immunostimulating complexes consist of a Quillaja saponin, cholesterol, phospholipids, and a corresponding antigen. Recently, another saponin from Quillaja brasiliensis was successfully tested in immunostimulating complexes, too. Based on the results of interaction studies, the formation of drug delivery systems such as immunostimulating complexes or similar self-assembled colloids is postulated for a variety of saponins.

\section{Introduction}

$\nabla$

\section{Properties of saponins}

Saponins are surface-active glycosides from different plants and marine organisms [1] and are subdivided into triterpenoid and steroid glyco-

\section{Abbreviations \\ $\nabla$}

BAM: $\quad$ Brewster angle microscopy

BHV-1: $\quad$ bovine herpesvirus type 1

COX-2: $\quad$ cyclooxygenase-2

DLS: dynamic light scattering

DMPC: dimyristoylphosphatidylcholine

DOPC: 1,2-dioleolyl-sn-glycero-3-phosphocholine

DPPC: dipalmitoylphosphatidylcholine

DPPG: dipalmitoylphosphatidylglycerol

Egg-PC: L- $\alpha$-phosphatidylcholine from egg yolk

FM: $\quad$ fluorescence microscopy

HIV: human immunodeficiency virus

HSV1: $\quad$ herpes simplex virus type 1

IL-1 $\beta$ : interleukin- 1 beta

IL-6: $\quad$ interleukin-6

iNOS: $\quad$ cytokine-inducible nitric oxide synthase

ISCOMs: immunostimulating complexes

LC: liquid-condensed

LE: liquid-expanded

MPL: $\quad$ monophosphoryl lipid A

PC: phosphatidylcholine

PSM: $\quad$ N-palmitoyl-D-erythro-sphingosylphosphorylcholine

QBS: Quillaja bark saponin

RAW 264.7: raw murine macrophage

TNF-alpha: tumor necrosis factor alpha

ZP: zeta potential sides based on the nature of their aglycone (or sapogenin) [2,3]. The aglycone of triterpene saponins consists of a $\mathrm{C}_{30}$ skeleton, whereas the steroid aglycone consists of a $\mathrm{C}_{27}$ skeleton subdivided into spirostane and furostane types. The difference between both types of steroid agly- 


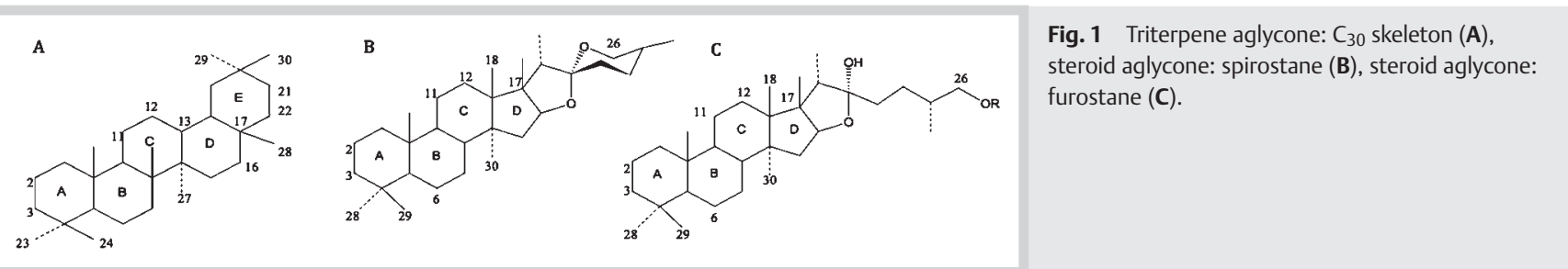

cones is the side chain linking to a spirocetal in spirostane saponins (๑ Fig. 1).

Triterpene saponins are divided in oleanane-type saponins and lupane-type saponins, among others ( $\bullet$ Fig. 2). Triterpene saponins are more widespread compared to steroid saponins [4]. The aglycone is linked via glycosidic bonds to different sugar moieties [5]. The attached sugar chains are mainly composed of D-glucose, D-galactose, D-glucuronic acid, D-fucose, D-xylose, L-rhamnose, or L-arabinose [4]. In most cases, the sugar chain is attached at C-3 (monodesmosidic). Bidesmosidic saponins contain another sugar chain at C-26 or C-28. The saponins and their bioactivity mainly differ due to their hydrophobic aglycone connected with different substituents (e.g., hydroxyl, hydroxymethyl, carboxyl, or acyl groups), and their hydrophilic sugar chains with differences in linkage and sugar moieties $[4,6]$. Saponins are connected with different properties: foaming in aqueous solution, emulsification [7], hemolytic activity [3,8], and antimicrobial, antiparasitic, and anticancer properties [3,9]. In $\odot$ Table 1, different saponins are listed with their effects discussed in this review. Saponins are not only used in medicine but also in the food and cosmetic industries as sweeteners, emulsifiers, or foam agents.

Some saponins are known as highly sweet substances, e.g., glycyrrhizin (triterpene saponin) from the roots of Glycyrrhiza glabra L. (Fabaceae) [10] and abrusoside A (triterpene saponin) from the leaves of Abrus precatorius L. (Fabaceae) [11]. Saponins are of interest in medicine essentially because of their immunological and pharmacological properties. Ginseng saponins from the roots of Panax ginseng (Araliaceae) exhibit wound healing effects on the skin of mice. Upon addition of ginseng saponins, the wounded area became smaller and the keratinocytes' migration rate was higher [12]. Kimura et al. [13] reported ginsengoside $\mathrm{Rb}_{1}$ to be the most potent saponin of total ginseng saponins in wound healing. Ginsengoside $\mathrm{Rb}_{1}$ (triterpene saponin) is able to increase tissue neovascularization, VEGF (vascular endothelial growth factor), and IL- $1 \beta$ production as well as macrophage accumulation. Antiviral activity was found for many saponins. Triterpene saponins from Sargentodoxa cuneata (Lardizabalaceae) and Thinouia coriacea (Sapindaceae; Chinese and Brazilian plants) were reported to have antiviral activity against HSV1. The saponin from the Brazilian plant inhibits DNA synthesis of HSV1, whereas the saponin from the Chinese plant inhibits viral capsid protein synthesis [14]. Amoros et al. [15] studied antiviral activity of a triterpene saponin from Anagallis arvensis (Primulaceae). This triterpene saponin inhibits replication of HSV1 and poliovirus type 2, which was shown by a reduction of virus production and inhibition of cytopathic effects. The saponin arganine C, extracted from the fruits of Tieghemella heckelii (Sapotaceae) exhibits antiviral activity against HIV by inhibiting HIV entry into cells [16]. In addition, a triterpene saponin with inhibitory activity against HIV-1 protease was extracted from the seeds of Aesculus chinensis (Sapindaceae) [17].
Another promising activity of some saponins is their cytotoxic and antiproliferative activity, which could be an interesting approach for the development of anticancer agents. Shao et al. [18] found that saponins from the shoots of Asparagus officinalis $\mathrm{L}$. (Asparagaceae) inhibit the growth of human leukemia HL-60 cells in culture. Saponins in the range of $75-100 \mu \mathrm{g} / \mathrm{mL}$ acted cytostatic and, in concentrations $>200 \mu \mathrm{g} / \mathrm{mL}$, they exhibited cytocidal effects on cells. The inhibitory effect of low doses of the saponin on the DNA synthesis of HL-60 cells was irreversible. Ruscogenin diglycosides of underground parts from Ruscus aculeatus (Asparagaceae), steroid saponins from rhizomes of Hosta sieboldii (Asparagaceae), triterpene saponins of the roots of Pulsatilla chinensis (Ranunculaceae) as well as steroid saponins from the aerial parts of Dracaena draco (Asparagaceae) also showed cytotoxic effects on leukemia HL-60 cells [19-22]. For other saponins, e.g., ginseng saponins, antiproliferative activity on human prostate cancer cells was observed by Liu et al. [23]. But there are plenty of other saponins with proven cytotoxic activity against cancer cells, e.g., furostanol saponins and steroid saponins from the rhizomes of Dioscorea panthaica (Dioscoreaceae), saponins from bulbs of Allium porrum L. (Amaryllidaceae), and a few more, although adequate control experiments with regular non-tumor cells are missing in most of the publications [24-26]. Another interesting finding of Weng et al. [27] was the mediation of the release of saporin out of the intracellular compartments into the cytosol without influencing the nature of the plasma membrane by saponins from Saponaria officinalis L. Saporin is a type I ribosome inactivating protein also from the plant of S. officinalis L. with cytotoxic activity when it is released in the cytosol of tumor cells. This was tested in vivo in a syngeneic tumor model. It seems very interesting that saponins biosynthesized from the same plant help the toxin moiety saporin to exercise its cytotoxicity.

Anti-inflammatory effects were found amongst others for triterpene saponins extracted from Caulophyllum thalictroides (Berberidaceae). These saponins are able to suppress the expression of COX-2, iNOS, and proinflammatory cytokines (TNF- $\alpha$, IL-1 $\beta$, and IL-6) in the adrenal glands of mice [28]. Yao et al. [29] observed anti-inflammatory activity of saponins from Chenopodium quinoa Willd. (Amaranthaceae), which is also used in the food industry. These saponins were tested on murine macrophage cells and showed inhibition of the production of inflammatory mediators (NO) and inflammatory cytokines (TNF- $\alpha$, IL- 6 ) in lipopolysaccharide-induced RAW 264.7 cells. In another study, escin (a natural mixture of triterpene saponins) extracted from the seeds of Aesculus hippocastanum (Sapindaceae) was observed to have synergistic anti-inflammatory effects with glucocorticoids tested in mice [30]. Kwak et al. [31] observed anti-inflammatory activity of the triterpene saponin loniceroside $\mathrm{C}$ from Lonicera japonica (Caprifoliaceae) against mouse ear edema. But there are some other saponins with anti-inflammatory activity such as fruticesaponin B, a bidesmosidic saponin from Bupleurum frutices- 
cens (Apiaceae), and the steroid saponin mannioside A from Dracaena mannii (Asparagaceae) [32,33].

Antimicrobial activity was observed for saponins from Medicago sativa, Medicago arborea, and Medicago arabica (Fabaceae). Saponins from M. arabica showed high antimicrobial activity against gram-positive bacteria (Bacillus cereus, Bacillus subtilis, Staphylococcus aureus, and Enterococcus faecalis) [34]. Khanna and Kannabiran [35] studied saponins from the leaves of Gymnema sylvestre (Apocynaceae) and Elclipta prostrata (Asteraceae). These saponins exhibit antibacterial and antifungal activity. The pure saponin fraction is more active against bacterial pathogens compared to the crude fraction. Further antimicrobial saponins are, for example, saponins from Sorghum bicolor L. (Poaceae), which exhibit an inhibitory effect on gram-positive bacteria, or triterpene saponins from Sapindus mukorossi Gaertn. (Sapindaceae) $[36,37]$. Antifungal activity was found for saponins extracted from Allium cepa L. (Amaryllidaceae). The main saponins with the highest antifungal activity were alliospiroside $\mathrm{A}$ and alliospiroside B [38]. Further saponins with antifungal activity were extracted from leaves of Solanum chrysotrichum (Solanaceae), from berries of Phytolacca tetramera (Phytolaccaceae), or from fruits of Capiscum sp. (Solanaceae) [39-41].

Adjuvant effects are also an important feature of saponins with regard to the development of adjuvanted vaccines. A long-known saponin fraction with this promising property is Quil A. Quil A is a heterogeneous saponin fraction extracted from the bark of Quillaja saponaria Molina (Quillajaceae) [42]. Quillaja saponins belong to the class of triterpene saponins [43]. Because of irritative and toxic potential, the use is limited to animal vaccines [44]. Further purification leads to the saponin fraction QS-21 [45]. This fraction is able to stimulate both the Th1 immune response by inducing Th1 cytokines (IL-2, IFN- $\gamma$ ) and the production of CTLs (cytotoxic T-Lymphocytes). QS-21 was reported to be acceptably safe and is therefore a promising vaccine adjuvant [45]. Saponins from $Q$. saponaria are used in ISCOMs in combination with cholesterol, phospholipids, and a corresponding antigen to enhance immune response. This is important, especially for subunit vaccines with weak immunogenictiy. Recently, Silveira et al. [46] found saponins (QB-90) from Quillaja brasiliensis (Quillajaceae) as promising adjuvant compounds because they reveal weak hemolysis and exhibit low cytotoxicity in comparison to Quil A. A further study by Fleck et al. [47] suggested adjuvant activity for QB-90 from Q. brasiliensis because of an enhanced immune response of mice after immunization with BHV-1. It was reported that QB-90 has the same ability as saponins from Q. saponaria to stimulate both the cellular and humoral immune response that was tested in a bovine viral diarrhea virus vaccine in mice [48]. Due to these promising properties, ISCOMs with QB-90 (IQB-90) from $Q$. brasiliensis were developed recently. They exhibit great structural similarity to ordinary ISCOMs consisting of saponins from $Q$. saponaria. IQB-90s are drug/antigen delivery systems with great potential for the development of vaccine adjuvants, consisting of $40-50 \mathrm{~nm}$ spherical cage-like particles composed of QB-90, cholesterol, phospholipids, and an antigen [49]. In the past, many different saponins were tested with regard to their pharmacological effects. Due to their multiple effects, they are considered to be very interesting plant ingredients for medicine.

\section{Langmuir film balance technique}

The Langmuir film balance is suitable to investigate model membrane systems at the molecular level to understand the organization of biological membranes and their interactions with differ-

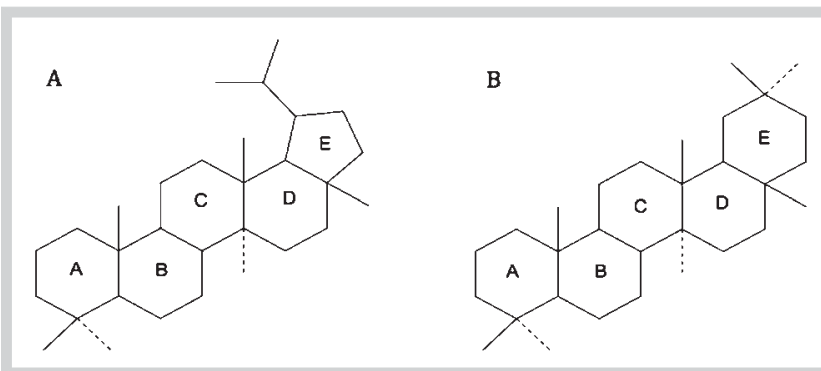

Fig. 2 Triterpene saponins from lupane type (A) and oleanane type (B).

ent molecules. A single molecule thick layer of organic compounds such as lipids, phospholipids, or glycolipids is fabricated on an aqueous subphase for imitating model membranes. Those lipids are insoluble amphiphilic molecules with a hydrophilic head group anchored in the aqueous subphase and a hydrophobic tail oriented towards the gas phase. This insoluble monolayer, which is formed at the air/water interface, is called Langmuir film or Langmuir monolayer. The ability to form a monolayer depends on the structure and properties (e.g., alkyl chain length, size, charge, and polarity of the hydrophilic head group) of amphiphilic molecules. Non-self-spreading lipids have to be dissolved first in an organic solvent (e.g., chloroform). The dissolved lipids are dropped onto the aqueous subphase. While the solvent evaporates, lipid molecules spread to form a Langmuir film at the air/ water interface. Hydrophilic head groups are in close contact by hydrogen bonds and hydrophobic tails by van der Waals forces. The aqueous phase is able to accommodate different molecules that are soluble in water (e.g., saponins). The measuring principle is based on the fact that the monolayer is compressed continuously by Teflon barriers during the experiment ( 0 Fig. 3).

The measured variable is the surface pressure that is continuously recorded by a paper Wilhelmy plate connected to a pressure sensor. The surface pressure $\pi$ (Eq. $\mathbf{1})$ is the difference between the surface tension of pure water $\sigma_{\mathrm{W}}\left(72.75 \mathrm{mN} / \mathrm{m}\right.$ at $\left.20^{\circ} \mathrm{C}\right)$ and the surface tension of the film-covered water surface $\sigma_{\mathrm{F}}$.

$\pi=\sigma_{\mathrm{W}}-\sigma_{\mathrm{F}}$

Eq. 1

The Wilhelmy plate is immersed into the subphase and the forces acting on the plate include gravity, surface tension, and upward forces. Prior to starting the measurement, the Wilhelmy plate is completely wetted with aqueous solution of the subphase. Due to the amphiphilic character of the film forming lipids, the latter are able to lower the surface tension of water, resulting in an increased surface pressure. The surface pressure $\pi$ is taken as a function of the molecular area A. This results in $\pi / \mathrm{A}$-isotherms ( $\odot$ Fig. 4). Example I ( $\odot$ Fig. 4) represents a condensed film. Prior to compression, the molecules at the air/water interface are disordered $(G)$. The hydrophilic head groups are immersed into the aqueous subphase and the hydrophobic tails are extended into the gaseous phase without any order. In this disordered gaseous-like state $(G)$, the molecules have a lot of space. At low compression, an LC film is formed, which corresponds to the state of a two-dimensional solid with numerous flaws. The space between the molecules decreases and hydrogen bonds between hydrophilic head groups are formed, which anchor the film into the subphase. Further compression results in a solid film (S). In this state, the molecules of the monolayer are tightly packed.

In example II ( $\odot$ Fig. 4 ), the film goes through further states. The gaseous phase is followed by an LE state. The plateau is a transi- 
Table 1 Overview of different saponins with their corresponding effects.

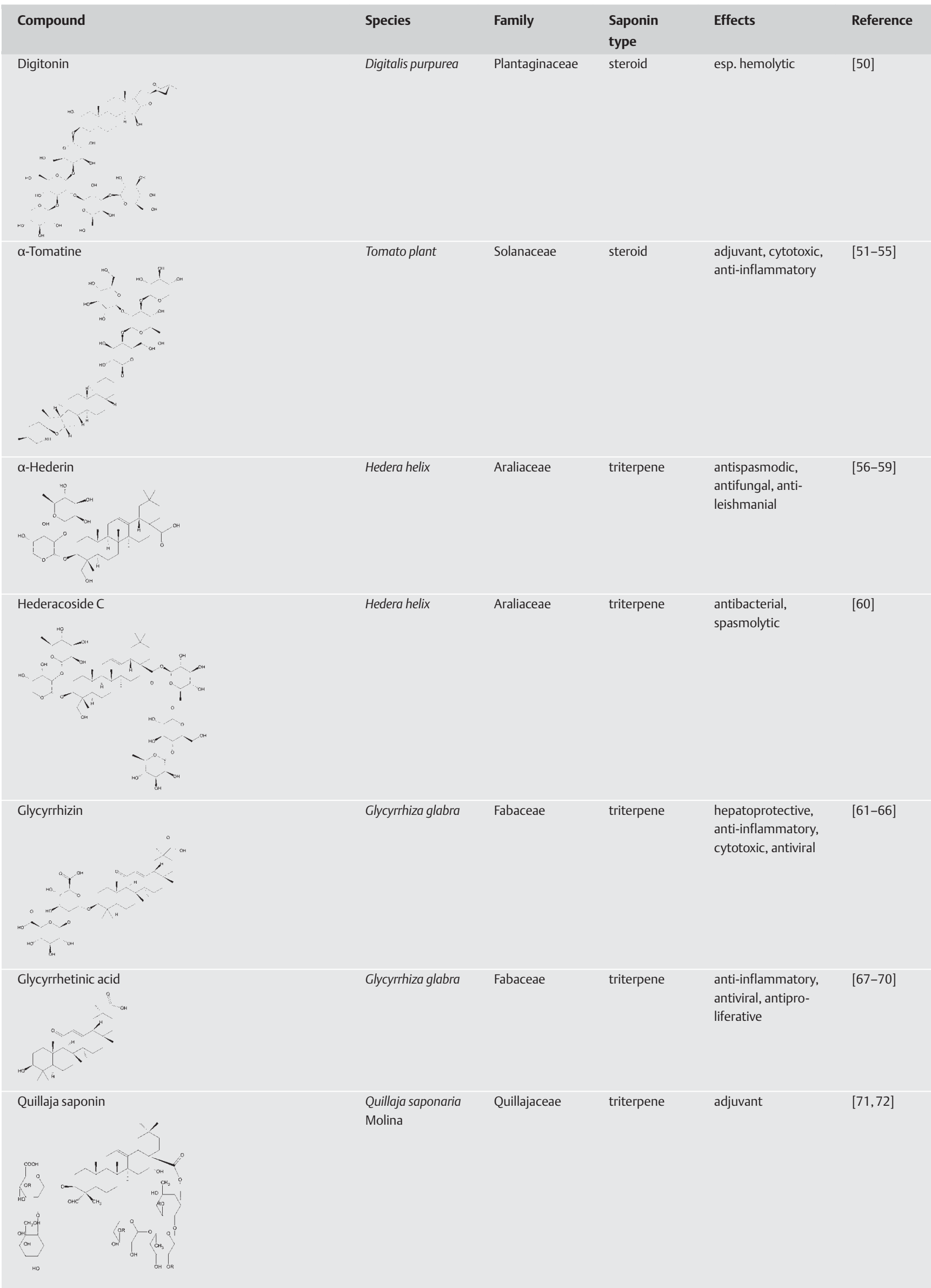


tion region between the LE and LC state, which is characterized by the coexistence of both phases. The point indicated by the arrow is the collapse point, which indicates the collapse of the monolayer. The monolayer falls into pieces that are pushed together, resulting in multilayers. The surface pressure as well as the molecular area at the collapse point are characteristic parameters of a specific monolayer. The phase behavior depends on the properties of the amphiphilic molecules as well as on experimental conditions such as $\mathrm{pH}$, temperature, etc.

The influence of saponins on model membrane systems: Langmuir film balance experiments

Since the hemolytic activity of saponins, to a varying extent depending on their properties [73], is a major drawback, elucidation of specific interactions between components in model membrane systems is very helpful in understanding the hemolytic activity and affinity of different saponins to liposomal membranes from Langmuir film balance experiments. Many publications report on interaction sudies of saponins in model membrane systems (cholesterol, phospholipids).

\section{Digitonin, a Steroidal Saponin with Membrane Permeabilizing Effects \\ $\nabla$}

As early as 1937, interaction studies of saponin and lipid film forming components were examined by Schulman and Rideal [74]. Using the Langmuir film balance, digitonin, a monodesmosidic steroid saponin from the seeds of Digitalis purpurea (Plantaginaceae), was injected into the subphase with a spread lipid film above. In this study, the interaction between digitonin and cholesterol was demonstrated by an increase in surface pressure. Thus digitonin appeared to penetrate into the cholesterol monolayer. Similarly, a slight penetration of digitonin into PC films was concluded from increasing surface pressure. These results were later confirmed [75]. The pioneering study of Schulman and Rideal [74] is based on the hypothesis that the extent of affinity between components depends on both polar and hydrophobic interactions.

About 40 years later, Akiyama et al. [76] hypothesized that the hemolytic activity of saponins is related to the extent of interactions with cholesterol in the membranes. Observations of a saponin-cholesterol interaction within the multibilayers of egg yolk lecithin were made by ${ }^{2} \mathrm{H}$ NMR spectroscopy. Depending on the digitonin/cholesterol ratio, different stages of complex formation resulted. Aggregated species were formed at a low mol ratio. These complexes indicated no stable complexes of digitonin and cholesterol. At a higher ratio, intermediate complexes formed, which means more rigid complexes were formed. Last, equimolecular complexes were formed with characteristics of a solid state, which were also stabilized by side chain methyl groups of cholesterol. Akiyama et al. [76] reported that the hydrophobic aglycone of saponins might be the major reason of interaction with cholesterol in membrane bilayers. Sugar moieties seem to be located externally outside of the bilayer and are able to stabilize the saponin-cholesterol complex. Nishikawa et al. [77] also suggested an influence of sugar complexicity for cholesterol binding. Complexation of saponins with cholesterol seems to depend mainly on hydrophobic aglycone and partially on hydrophilic sugar moieties. Akiyama et al. [76] confirmed the results of Segal et al. [78] that the aglycone part of saponins is mainly responsible for the hemolytic activity.

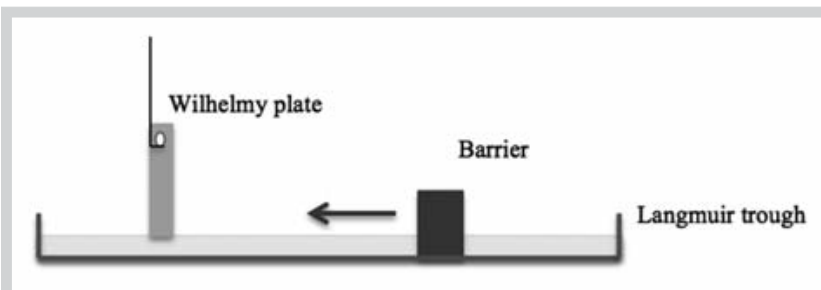

Fig. 3 Schematic representation of a Langmuir trough with one movable barrier that compresses the monolayer. The direction of the movable barrier is indicated by the arrow. The surface tension was analyzed with a Wilhelmy plate at the given time points.

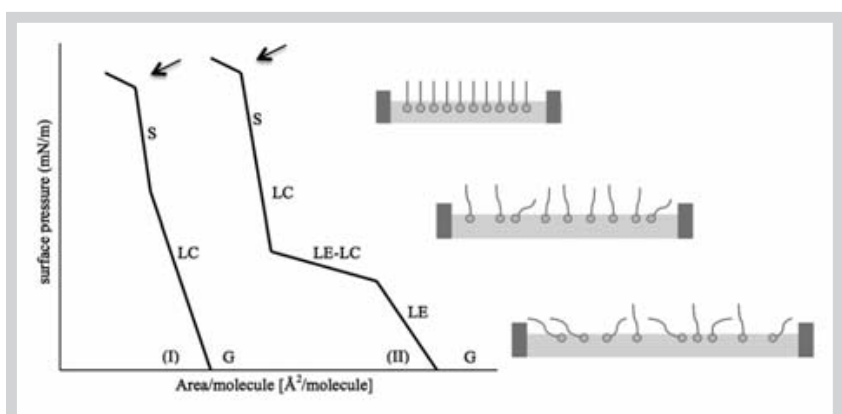

Fig. 4 Langmuir isotherms of surface pressure versus area; $\mathrm{S}=$ solid, $\mathrm{LC}=$ liquid-condensed, LE = liquid-expanded, G = gaseous. The collapse point of the monolayer is indicated by the arrow.

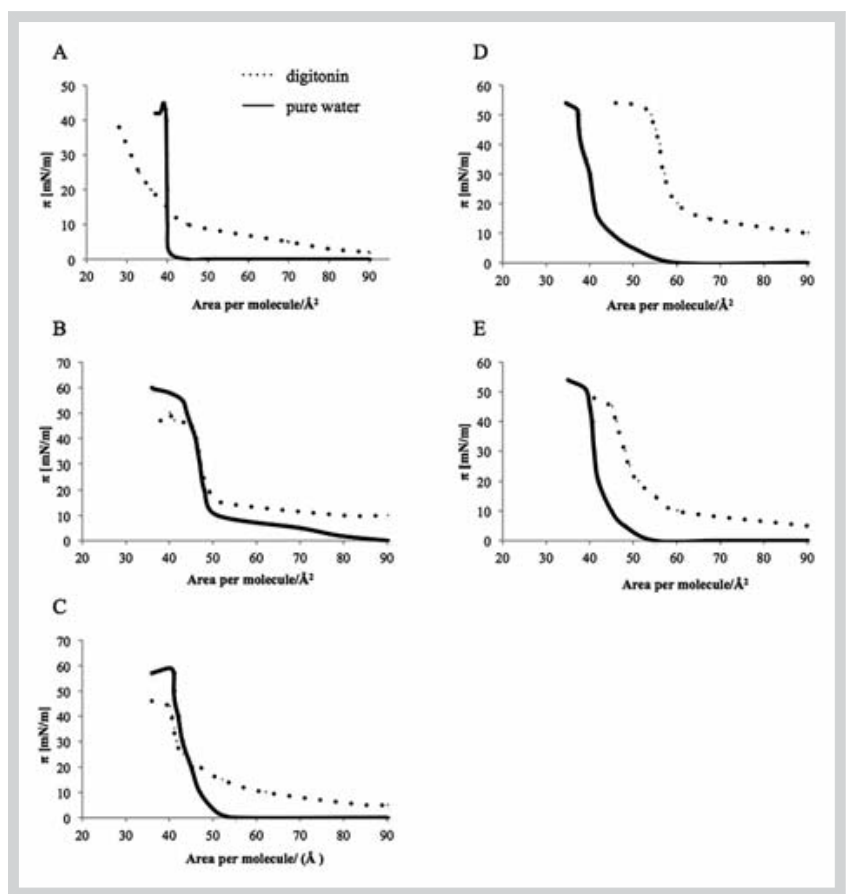

Fig. 5 Langmuir isotherms of cholesterol (A), DPPC (B), DPPG (C), DPPC/ cholesterol (D), and DPPG/cholesterol (E); subphase: pure water and aqueous digitonin solution. (Redrawn from Korchowiec et al. [79].)

Korchowiec et al. [79] also conducted Langmuir film balance experiments ( Fig. 5) with the steroid saponin digitonin with the 
Table 2 General cytotoxicity and membrane toxicity ( $\mathrm{IC}_{50}$ values) and reduction in surface tension ( $\mathrm{EC}_{50}$ values) and critical micelle concentrations (CMC) of tested saponins by Böttger et al. [83].

\begin{tabular}{|c|c|c|c|c|}
\hline & \multicolumn{2}{|l|}{$\mathrm{IC}_{50} / \mu \mathrm{M}$} & $\mathrm{EC}_{50} / \mu \mathrm{M}$ & $\mathrm{CMC} / \mu \mathrm{M}$ \\
\hline & General cytotoxicity & Membrane toxicity & \multicolumn{2}{|c|}{ Reduction in surface tension } \\
\hline$\alpha$-Hederin & 35 & 29 & 4 & 13 \\
\hline Hederacoside C & $>164$ & $>164$ & 10 & 82 \\
\hline Digitonin & 13 & 15 & 8 & 163 \\
\hline Glycyrrhizin & $>119$ & $>238$ & 128 & $>1429$ \\
\hline Glycyrrhetininc acid & 101 & 292 & 16 & 106 \\
\hline
\end{tabular}

aim to study its impact on model lipid membranes and to understand hemolytic activity. Monolayers were formed on a digitonin aqueous subphase consisting of cholesterol, DPPC, DPPG and mixed DPPC/cholesterol, and DPPG/cholesterol.

A monolayer of cholesterol on a digitonin aqueous subphase suggests penetration of digitonin into the monolayer at low surface pressure. At high surface pressure, cholesterol is expelled into the subphase by digitonin, resulting in a shift to a smaller molecular area. Furthermore, the interaction between the saponin and mixed monolayers (DPPC/cholesterol, DPPG/cholesterol) is much higher compared to the pure DPPC and DPPG monolayer because of a shift to higher molecular areas. Strong interactions between digitonin and mixed monolayers were also characterized by higher molecular areas at the collapse point. A higher affinity of digitonin to DPPC compared to DPPG was found in the mixed monolayers. It may be concluded that the nature of phospholipids in the mixed monolayers also determines the extent of interaction with saponins. All in all, a higher affinity of digitonin was observed for cholesterol than for phospholipids, because at the high surface pressure, cholesterol was expelled from the monolayer. In accordance with other research groups, they assumed that the aglycone part of digitonin is responsible for the interaction with the sterol part of cholesterol and that the sugar part may interact with the hydroxyl group. Based on these studies, cholesterol is likely to be an important component in membranes with regard to interactions with digitonin. If cholesterol is present in model membrane systems, digitonin penetrates it easily. This was confirmed by Yu and Choi [80] and Sudji et al. [81]. Yu and Choi [80] found that digitonin permeabilizes liposomal membranes consisting of phosphatidylcholine, dicetylphosphate, and cholesterol but has no influence on liposomes without cholesterol. Sudji et al. [81] studied the influence of digitonin on natural and model membranes. The results suggest that digitonin promotes membrane permeability only in the presence of cholesterol depending on both concentrations. At a low concentration, digitonin induces membrane permeabilization without membrane destruction. Further studies by Gilabert-Oriol et al. [50] refer to the membrane permeabilizing effects of digitonin. In comparison with other saponins, such as glycyrrhizin (monodesmosidic triterpene saponin), digitonin indicates moderate permeabilizing effects on cell membranes and substantial effects on lysosomal membranes as well as high hemolytic activity. Böttger et al. [82] also demonstrated high toxicity (general cytotoxicity, membrane toxicity) for digitonin correlated with high surface activity, as can be seen in Table 2. A differentiation was made between general cytotoxicity and membrane toxicity. The general cytotoxicity describes the intolerance of the cells to proliferate after the addition of saponins. Membrane toxicity is assessed by the amount of released intracellular enzyme LDH. From these results, a correlation between high affinity for membrane cholesterol, high permeabi- lizing effects, high hemolytic activity, and high surface activity of digitonin seems likely. A high affinity to membrane cholesterol and building of cholesterol-digitonin complexes leads to a loss of cholesterol in membranes. The membrane gets instable and permeable because cholesterol plays a major role for membrane stability $[83,84]$.

\section{Hederacoside $\boldsymbol{C}, \boldsymbol{\alpha}$-Hederin: Triterpene Saponins from Ivy with Differences in Membrane Toxicity \\ $\nabla$}

Besides digitonin, a variety of further saponins was studied with regard to interactions with cholesterol in membranes and resulting permeabilizing effects [85-87]. Böttger et al. [82] also found a correlation between a perturbing biological membrane and surface activity for $\alpha$-hederin and hederacoside $C$, two different triterpene saponins extracted from ivy (Hedera helix). Cholesterol seems to be essential for saponins to induce pore formation of membranes $[86,87]$. Due to steric constraints of saponin-cholesterol complexes, the membrane gets porous, releasing intracellular components such as the intracellular enzyme LDH.

- Table 2 suggests a correlation between general cytotoxicity and membrane toxicity. A high general cytotoxicity of $\alpha$-hederin coincides with high membrane toxicity. For $\alpha$-hederin, a high membrane permeabilizing effect was found along with a low CMC value and a high potential in reduction of surface tension. In contrast, hederacoside $\mathrm{C}$ shows much lower general cytotoxicity along with lower membrane toxicity. The CMC value of hederacoside $C$ is much higher. Hederacoside $C$ seems to be a biologically less active amphiphilic substance with low surface activity. Böttger and Melzig [83] investigated the influence of $\alpha$-hederin and hederacoside $C$ on cell membrane cholesterol. They determined both the release of cholesterol from the cell membrane and the inclusion into the cell membrane in the presence of saponins. Besides confirming the correlation between general cytotoxicity and membrane toxicity for hederacoside $C$ and $\alpha$-hederin, they found a relationship between membrane toxicity of saponins and their ability of inducing cholesterol liberation of cellular membranes and of inhibiting cholesterol uptake. That means saponins with high membrane toxicity and general cytotoxicity such as $\alpha$-hederin significantly change the cell membrane cholesterol content, which results in membrane pertubation. $\alpha$-Hederin is suggested to form complexes with cholesterol. A high toxicity of $\alpha$-hederin was also observed by other research groups $[8,88]$. In contrast, hederacoside $C$ is of high interest due to its low membrane toxicity.

Langmuir film balance studies with respect to $\alpha$-hederin and hederacoside $C$ were made by Wojciechowski et al. [89] on monolayers consisting of cholesterol and DPPC as model membranes. $\alpha$-Hederin increased the surface pressure much more (by nearly 
$20 \mathrm{mN} / \mathrm{m}$ ) than hederacoside C. $\alpha$-Hederin is a monodesmosidic saponin that arises from bidesmosidic hederacoside $\mathrm{C}$ by saponification. Due to the second sugar chain in hederacoside $C$, the negative ion charge of the carboxyl group is neutralized, possibly leading to a reduction of surface activity. $\alpha$-Hederin is more surface active than hederacoside $C$, which is in accordance with previous studies [83].

Saponins in the subphase were tested with pure DPPC monolayers and mixed DPPC/cholesterol monolayers with regard to surface pressure versus time ( $\boldsymbol{0}$ Fig. $\mathbf{6}$ ). On pure DPPC monolayers, hederacoside $C$ has no influence because no changes in surface pressure result with time. In contrast, $\alpha$-hederin affects a DPPC monolayer by increasing surface pressure (about $45 \mathrm{mN}$ / $\mathrm{m})$, possibly due to its amphiphilic character, resulting in penetration into the monolayer. A further increase in surface pressure was recorded upon addition of cholesterol in mixed DPPC/cholesterol monolayer. An increase in surface pressure was also observed for hederacoside $C$ with mixed monolayers. This again supports cholesterol's importance for the saponin interaction. In accordance with previous studies, $\alpha$-hederin seems to have a higher affinity of interacting with model membrane systems compared to hederacoside $\mathrm{C}$.

\section{Membrane Permeabilizing Effects of Glycyrrhizin and Its Aglycone Glycyrrhetinic Acid \\ $\nabla$}

Sakamoto et al. [90] studied the interactions between glycyrrhizin and model membrane systems consisting of PSM, DOPC, and cholesterol with Langmuir film balance. They carried out experiments with single, binary and ternary monolayers (PSM, DOPC, cholesterol) on a Tris buffer subphase containing $\mathrm{NaCl}$ with or without glycyrrhizin. Glycyrrhizin is categorized as a monodesmosidic triterpene saponin extracted from G. glabra L. (Fabaceae) with a triterpene backbone and attached to two glucuronic acid groups. As depicted in $\odot$ Fig. 7 B, increasing amounts of glycyrrhizin result in a shift of the ternary monolayer isotherm to larger molecular areas. At the collapse point of the isotherms, the same surface pressure $(\sim 48 \mathrm{mN} / \mathrm{m})$ is observed for all different concentrations of glycyrrhizin. The isotherms of pure cholesterol, PSM and DOPC monolayers as well as the isotherms of mixed PSM/ cholesterol and PSM/DOPC monolayers on a subphase containing glycyrrhizin ( $\bullet$ Fig. $\mathbf{~ C ~}$ ) are expanded to larger molecular areas compared to isotherms of monolayers on a subphase without glycyrrhizin ( $\odot$ Fig. $7 \mathrm{~A})$. The surface pressure and molecular area at the collapse point ( $\odot$ Fig. $7 \mathrm{C}$ ) seem to be the same compared to - Fig. 7 A. Sakamoto et al. [90] supposed an initial integration of glycyrrhizin into the ternary monolayer that would be expelled from the surface with further compression. After being excluded from the monolayer, glycyrrhizin may attach to cholesterol right underneath the monolayer. Due to the surface potential measurement of the pure PSM monolayer on a subphase containing glycyrrhizin, an initially positive slope of the PSM isotherm followed by a negative slope was observed. Based on this observation, they supposed an exclusion of glycyrrhizin simultaneously with the LE/LC phase transition of PSM (see $\odot$ Fig. 7 A). Further studies by BAM and FM revealed membrane-disrupting activity of glycyrrhizin at a concentration of $50 \mu \mathrm{M}$ due to an affinity to cholesterol. Again, cholesterol turns out to be an essential component for interactions with glycyrrhizin. The binding of cholesterol by glycyrrhizin results in a lack of cholesterol at the surface, which is associated with a membrane permeabilizing effect.

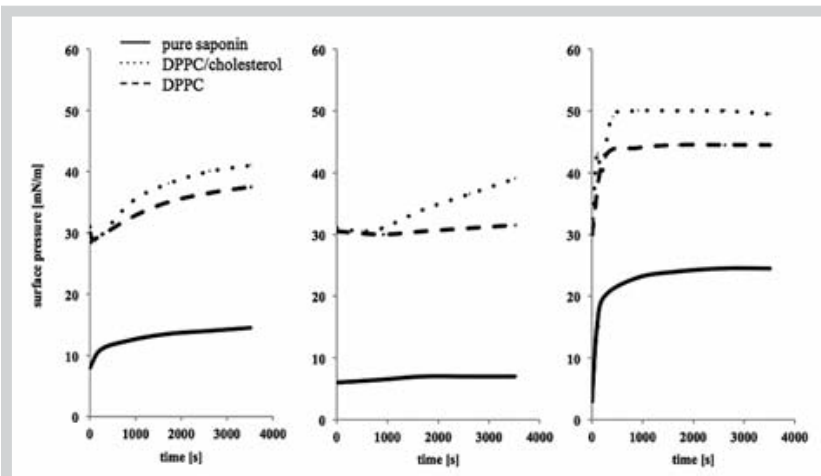

Fig. 6 Surface pressure versus time of pure saponin, DPPC, and DPPC/ cholesterol monolayers; subphase: ammonium glycyrrhizate (left) hederacoside C (middle); $\alpha$-hederin (right). (Redrawn from Wojciechowski et al. [89].)

Recently, the interfacial behavior of glycyrrhetinic acid, the aglycone of glycyrrhizin, was studied [91]. Equal to glycyrrhizin, glycyrrhetinic acid is expelled out from a ternary monolayer of PSM, DOPC, and cholesterol upon compression. Glycyrrhetinic acid interacts with cholesterol, which participates in surface-associated aggregates of the lipids, the so-called microdomains or lipid rafts. The results generally reveal a stronger affinity of glycyrrhetinic acid to lipids compared to glycyrrhizin (from previous studies) as shown in $\bullet$ Fig. 8. The $\pi /$ A-isotherm of the ternary monolayer on a subphase containing glycyrrhetinic acid results in a shift towards larger molecular areas due to stronger interactions [90]. Langmuir film balance experiments were also made with an ammonium salt of glycyrrhizin [89] (compare ๑ Fig. 6). Penetration of ammonium glycyrrhizate into pure DPPC as well as into mixed $\mathrm{DPPC} /$ cholesterol monolayers was comparable in terms of similar values in surface pressure of about 35 to $40 \mathrm{mN} / \mathrm{m}$. Because of similar surface pressure values for pure DPPC and mixed DPPC/ cholesterol monolayers, glycyrrhizate seems not to differentiate between these lipids. Further studies provided stability constants of binary saponin-lipid complexes that demonstrate that ammonium glycyrrhizate is not able to form complexes with cholesterol or DPPC, whereas $\alpha$-hederin and hederacoside C do so. The affinity of ammonium glycyrrhizate towards the lipids is not as high as that of the glycyrrhetinic acid. This is connected to a low membrane activity.

The membrane toxicity of glycyrrhizin and glycyrrhetininc acid as well as their general cytotoxicity was also studied by Böttger et al. [82,83]. Glycyrrhizin and glycyrrhetininc acid exhibit rather low toxicity, both general toxicity and membrane toxicity, which are associated with a low surface activity and a high CMC value in the case of glycyrrhizin ( $\boldsymbol{O}$ Table 2 ). This again suggests a correlation between general cytotoxicity and membrane toxicity as was also observed for $\alpha$-hederin and hederacoside C. The much higher surface activity of glycyrrhetinic acid may be related to a stronger affinity to lipids compared to glycyrrhizin, which was also observed by Sakamoto et al. $[90,91]$. The low toxicity of glycyrrhizin is also in accordance with studies of Gilabert-Oriol et al. [50] and Melzig et al. [92]. Gilabert-Oriol et al. [50] tested permeabilizing effects of saponins on cell membranes, lysosomal membranes, and membranes of red blood cells. According to these studies, glycyrrhizin exhibits no membrane permeabilizing effects on cell membrane and lysosomal membranes, and no lytic activity in 
tested concentrations compared to the tested steroid saponin digitonin. Gilabert-Orial et al. [50] supposed a structure-activity relationship related to sugar moieties. Glycyrrhizin is a triterpene saponin with two attached sugar moieties, while digitonin is a steroid saponin with a branched sugar chain causing a high membrane permeabilizing effect and a high hemolytic effect. When comparing the triterpene saponins $\alpha$-hederin and glycyrrhizin, $\alpha$-hederin exhibits much higher membrane activity despite some structural similarity. Only $\alpha$-hederin is able to complex cholesterol and DPPC. Wojciechowski et al. [89] supposed that a single carboxylic group of $\alpha$-hederin is more active than three carboxylic groups in a glycyrrhizin molecule and that the ketone group attached to the aglycone presumably prevents the interaction with cholesterol and DPPC.

\section{o-Tomatine: A Glycoalkaloid with High Affinity for Cholesterol \\ $\nabla$}

There is another interesting saponin from the tomato plant, the glycoalkaloid $\alpha$-tomatine. It is widely accepted that $\alpha$-tomatine is able to disrupt membranes in the presence of cholesterol [93]. Therefore, studying its interactions with model membrane systems is of special interest. Morrow et al. [94] reported adjuvant activity of $\alpha$-tomatine. It stimulates both the humoral and cellular immune response, thus enhancing immunogenity of subunit vaccines. Furthermore, it also has great potential in the treatment of cancer.

Stine et al. [95] conducted interaction studies with $\alpha$-tomatine by Langmuir film balance experiments. As model membrane systems, DMPC and different sterols were used. Cholesterol, cholestanol, and epicholesterol exhibit the same molecular area at the collapse point on a subphase containing $\alpha$-tomatine. The isotherms of mixed sterol/DMPC monolayers on an $\alpha$-tomatine subphase shift to higher molecular areas and to higher values of surface pressure. $\otimes$ Fig. $9 \mathrm{~A}$ shows the surface pressure change versus time of cholesterol and DMPC on a subphase of $\alpha$-tomatine, revealing a stronger interaction with cholesterol compared to that with DMPC. Upon addition of $\alpha$-tomatine in various concentrations, an increase in the final surface pressure at a given time was observed for the mixed DPPC/cholesterol monolayer with increasing saponin concentrations ( $\odot$ Fig. 9B). All in all, $\alpha$-tomatine has a great affinity to cholesterol and some other sterols, depending on the structure. Interaction of $\alpha$-tomatine with mixed $\mathrm{DMPC} /$ sterol monolayers is also given.

As known from the literature with regard to complex formation between glycolalkaloids and cholesterol [96], a complexation of $\alpha$-tomatine and cholesterol (1:1) is assumed likewise because of visible aggregates detected by BAM. The authors suppose that a cohesion of these complexes is given by hydrogen bonds between the hydroxyl groups of the sugar moieties and the hydroxyl group in sterol $[96,97]$. Depending on sterol structure, the strength of interaction with $\alpha$-tomatine differs, which is associated with different values in surface pressure. The interaction of $\alpha$-tomatine of various concentrations with binary monolayers consisting of DMPC/cholesterol or sphingolipid (egg sphingomyelin)/cholesterol was studied by Langmuir film balance experiments and BAM [98]. In agreement with previous studies, an interaction between $\alpha$-tomatine and mixed monolayers of DMPC and cholesterol has been confirmed ( $\bullet$ Fig. 9C). Likewise, an increased concentration of $\alpha$-tomatine results in an increased surface pressure. - Fig. 9D presents a mixed monolayer of egg sphingomyelin and
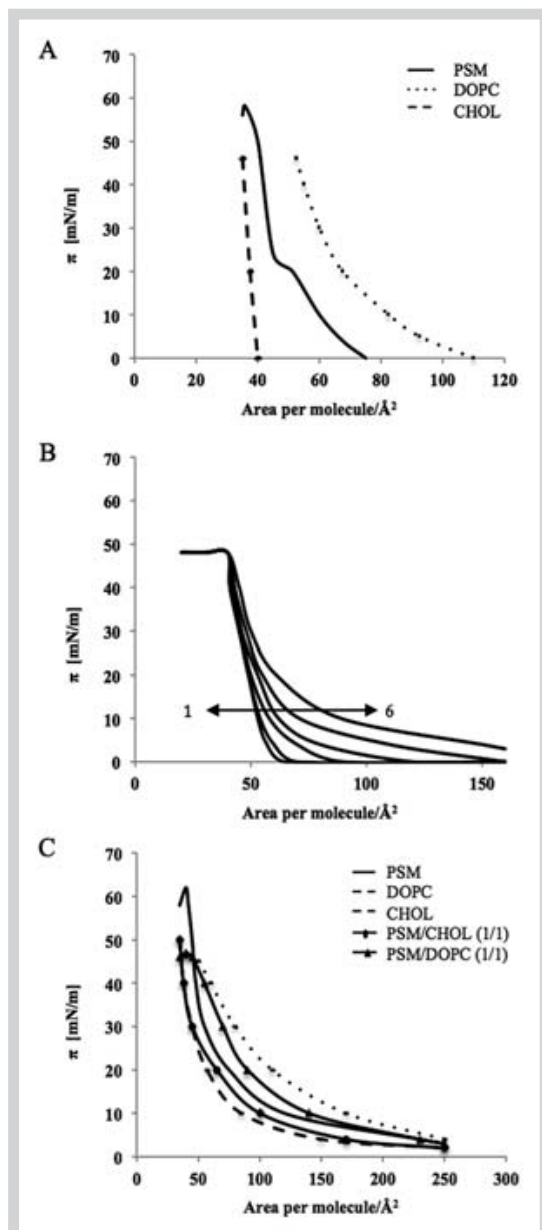

Fig. 7 Langmuir isotherms of pure cholesterol, PSM, and DOPC monolayers on a Tris buffer subphase containing $\mathrm{NaCl} ; \mathbf{A} \quad \mathrm{LE} / \mathrm{LC}$ phase transition of PSM isotherm (arrow); B isotherms of ternary equimolar cholesterol/ PSM/DOPC monolayers on Tris buffer subphase containing $\mathrm{NaCl}$ and different amounts of glycyrrhizin (1: PSM/ DOPC/cholesterol (1/1/1), 2: $\mathrm{C}_{\mathrm{GC}}: 1 \mu \mathrm{M}$; 3: $\mathrm{C}_{\mathrm{GC}}: 5 \mu \mathrm{M} ; 4: \mathrm{C}_{\mathrm{GC}}$ : $10 \mu \mathrm{M} ; 5: \mathrm{C}_{\mathrm{GC}}: 25 \mu \mathrm{M}$; 6: $\left.\mathrm{C}_{\mathrm{CC}}: 50 \mu \mathrm{M}\right)$; $\mathrm{C}$ isotherms of pure cholesterol, PSM, and DOPC monolayers and isotherms of binary PSM/ cholesterol (1/1) and PSM/DOPC (1/1) monolayers on a Tris buffer subphase containing $\mathrm{NaCl}$ and glycyrrhizin $(50 \mu \mathrm{M})$. (Redrawn from Sakamoto et al. [90].)

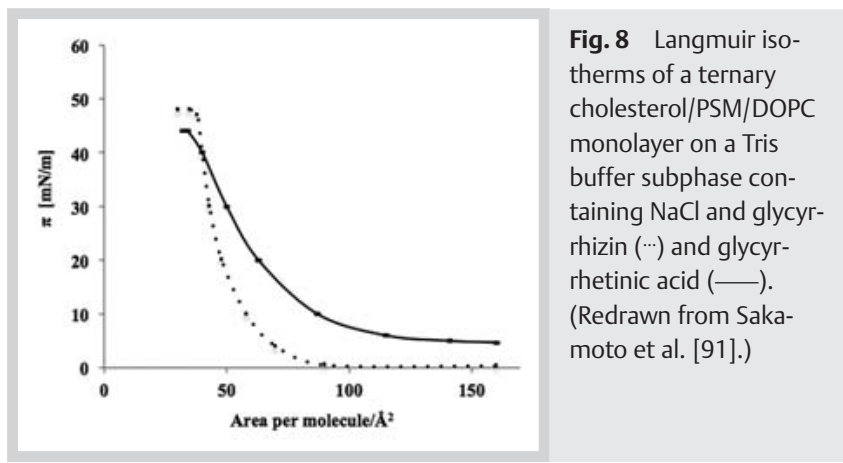

cholesterol on a subphase with different concentrations of $\alpha$-tomatine. An initial positive slope is followed by a negative slope, which means surface pressure decreases with progressing time. Besides, a larger concentration of $\alpha$-tomatine is needed to achieve the same surface pressure compared to the DMPC/cholesterol monolayer. Furthermore, the determined interfacial binding constants confirm a stronger interaction of $\alpha$-tomatine with the $\mathrm{DMPC} /$ cholesterol monolayer compared to the egg sphingomyelin/cholesterol monolayer. This may also be recognized by the highest values of surface pressure for the mixed monolayer of DMPC/cholesterol ( Fig. 9B). It was hypothesized that less interaction between $\alpha$-tomatine and the egg sphingomyelin/cholesterol monolayer is due to a stronger interaction between egg sphingomyelin and cholesterol than between cholesterol and 
phospholipid as described previously by Ramstedt and Slotte [99]. As mentioned above, Stine et al. [95] claim that hydrogen bonds are essential for complexation. Consequently, a hydrogen binding between the cholesterol hydroxyl group and the sphingomyelin amide group is likely. Because of the interaction between the lipids, complexation of $\alpha$-tomatine and cholesterol decreases, which is in line with a higher concentration of $\alpha$-tomatine required for the same surface pressures compared to DMPC/ cholesterol.

The surface pressure versus time of a ternary mixed monolayer of DMPC/egg sphingomyelin/cholesterol on an $\alpha$-tomatine subphase of a given concentration is between those of binary monolayers. The lowest surface pressure is observed for the pure egg sphingomyelin monolayer followed by the binary monolayer of egg sphingomyelin/cholesterol. The highest surface pressure is observed for the binary mixture of DMPC/cholesterol [98]. These results again suggest that $\alpha$-tomatine has a higher affinity for DMPC in combination with cholesterol compared to egg sphingomyelin, respectively. Furthermore, the authors analyzed different mole ratios of cholesterol and $\alpha$-tomatine ( 0 Fig. 10).

The isotherm of a $1: 1$ mixture represents a stable monolayer with a high collapse point above $45 \mathrm{mN} / \mathrm{m}$. The molecular area at the collapse point of the $1: 1$ mixture is not much higher than that of a pure cholesterol monolayer. This may be due to a loss of $\alpha$-tomatine molecules into the subphase, which are not complexed by cholesterol. If cholesterol is present in larger amounts ( $3: 1$ mole ratio), $\alpha$-tomatine molecules are not likely to dissolve in the subphase because sufficient interaction partners are present in the monolayer, resulting in a shift of the isotherm to larger molecular areas.

Walker et al. [98] concluded that ternary monolayers of egg sphingomyelin, cholesterol, and $\alpha$-tomatine are less stable than binary monolayers of cholesterol and egg sphingomyelin because of the expanded isotherm ( $\bullet$ Fig. 11), and the shift to smaller molecular areas is due to instability of the ternary monolayer. Possibly, $\alpha$-tomatine forms complexes with cholesterol, which are expelled from the monolayer. All in all, Walker et al. [98] explored some important relationships. Their results suggest a stronger monolayer activity of $\alpha$-tomatine when DMPC is present compared to egg sphingomyelin. Either $\alpha$-tomatine shows a stronger affinity for DMPC compared to egg sphingomyelin, or the complex formation of DMPC and cholesterol is much lower compared to egg sphingomyelin and cholesterol, so that an interaction may be fascilitated. $\alpha$-Tomatine also shows a strong interaction with pure cholesterol.

\section{Quil A: A Promising Adjuvant in Vaccines}

$\nabla$

A widely studied and promising saponin is Quil A, which is used in ISCOMs as an adjuvant in vaccines. To understand the interaction of Quil A in ISCOMs (with cholesterol and phospholipids), Langmuir film balance experiments were conducted ( $\odot$ Fig. 12). Paepenmüller and Müller-Goymann [100] suggest an interaction between Quil A and cholesterol.

Langmuir isotherms of a cholesterol monolayer on an aqueous subphase compared to a Quil A subphase are different. On the Quil A subphase, cholesterol molecules require more space in the monolayer, resulting in higher molecular areas because of an integration of Quil A molecules. Another indication of an interaction between Quil A and cholesterol is the increase in surface pressure upon the addition of Quil A into the subphase. Quil A re-

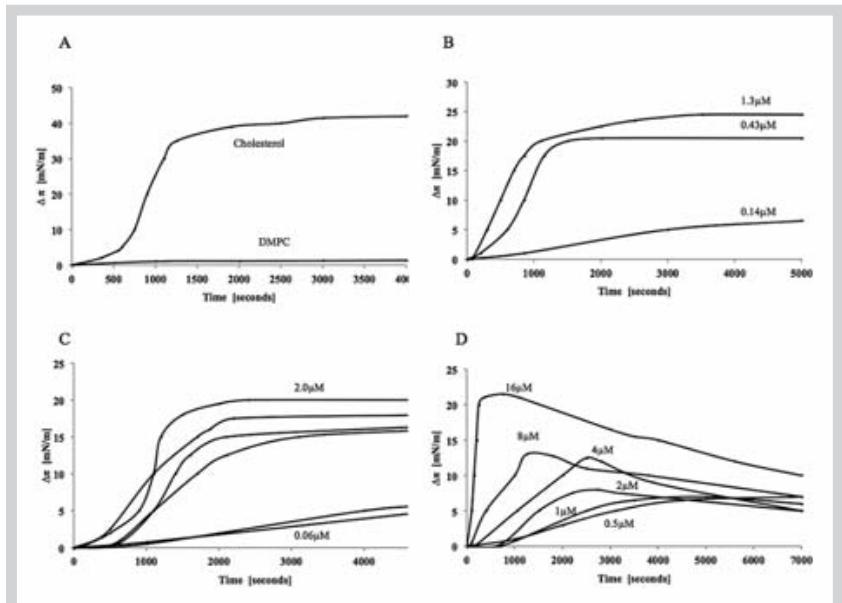

Fig. 9 Surface pressure versus time of a $\mathbf{A}$ monolayer of pure cholesterol and pure DMPC on an $\alpha$-tomatine subphase $(1.3 \mu \mathrm{M})$; B mixed monolayer of DMPC/cholesterol (7/3 mole ratio) on a subphase with different concentrations of $\alpha$-tomatine. In each case $\alpha$-tomatine was added to a subphase of $\mathrm{pH} 7(0.05 \mathrm{M}$ phosphate buffer, $0.10 \mathrm{M} \mathrm{NaCl})$ at a surface pressure of $10 \mathrm{mN} / \mathrm{m}$; $C$ mixed monolayer of DMPC/cholesterol (7/3 mole ratio) on an $\alpha$-tomatine subphase of different concentrations $(2.0 \mu \mathrm{M}, 1.0 \mu \mathrm{M}$, $0.5 \mu \mathrm{M}, 0.25 \mu \mathrm{M}, 0.125 \mu \mathrm{M}$, and $0.06 \mu \mathrm{M})$; D mixed monolayer of egg sphingomyelin/cholesterol (7/3 mole ratio) on an $\alpha$-tomatine subphase of given concentrations. (A and $\mathbf{B}$ redrawn from Stine et al. [95]; $\mathbf{C}$ and $\mathbf{D}$ redrawn from Walker et al. [98].)

duces interface tension because of its amphiphilic character and penetrates into the monolayer. This may also give evidence of an impact of saponins on biological membranes. No interaction was observed between Quil A and PC because no change in surface pressure occured.

The major role of cholesterol in terms of interaction between saponin and biological membranes has been confirmed in the past by many research groups. In this context, Wojciechowski et al. [101] focused on Langmuir film balance experiments of phospholipid mono- and bilayers (DPPC) and QBS. Concentrations of QBS above the CMC were chosen. The authors obtained coincident isotherms for a DPPC monolayer spread directly onto a QBS subphase and for an aqueous QBS solution. They suggested an entrapment of the phospholipid into QBS micelles of the subphase instead of the formation of a Langmuir monolayer. Therefore, they claimed a different setup prior to the measurement, that is the monolayer spreading on an aqueous subphase followed by an exchange with a QBS solution. In this case a different isotherm was obtained, that in part follows the isotherm of a DPPC monolayer on a water subphase at high surface pressures. Rattanapak et al. [102] investigated the interaction between Quil A and a lipid monolayer with respect to the incorporation of Quil A in lipid nanoparticles for noninvasive immunization via the topical route. Rattanapak et al. [102] placed special focus on other Quil A-containing nanoparticles with a promising perspective of transcutaneous immunization. Lipid nanoparticles with a negative charge were used in the size range of approximately 134-200 nm: liposomes, transferosomes, ethosomes, and cubosomes. The ingredients of the lipid nanoparticles are listed in 0 Table 3. Kohli and Alpar [103] found that only negatively charged nanoparticles in the size range of $50-500 \mathrm{~nm}$ permeate the skin with the aim of transdermal vaccination. 
Particle size investigations by DLS demonstrated an increase in particle size and ZP upon the addition of the adjuvants (Quil A, MPL). Determination of peptide entrapment efficiency resulted in a decreased entrapment in lipid nanoparticles with the adjuvants (Quil A, MPL).

The authors also performed Langmuir film balance experiments ( Fig. 13). Quil A forms no condensable monolayer because no collapse point was observed. Quil A and MPL reduce the surface pressure at the collapse point of the monolayer of $\mathrm{PC} /$ phytantriol and the isotherm shifts towards larger molecular areas, hinting at an interaction between the additives and PC monolayer as well as the phytantriol monolayer. This is an important prerequisite for the formation of lipid nanoparticles with additional adjuvant Quil A.

Many interaction studies were made in the past to understand the toxicity and affinity of different saponins to model membrane systems. A promising saponin with fairly low toxicity and high adjuvant activity is Quil A extracted from the bark of $Q$. saponaria Molina. Because of its interaction with cholesterol, and apparently also phospholipids, it can be used in ISCOMs described below. However, other saponins such as hederacoside $C$ or glycyrrhizin seem to be promising saponins because of their low membrane toxicity. There are plenty of other saponins that have been tested for their membrane activitiy, but with different methods than the Langmuir film balance experiments.

\section{Hemolytic Activity of Saponins \\ $\nabla$}

The hemolytic property of saponins is a characteristic feature and represents a major drawback for the development of adjuvanted vaccines and anticancer agents. Saponins are able to lyse erythrocytes, resulting in a release of hemoglobin. The extent of hemolysis is dependent on the type and chemical structure of saponins. In the past, many researchers investigated the extent of hemolytic activity of different saponins as well as dependency on certain structural properties (structure-activity relationship [SAR]). Segal et al. [78] studied the effect of the ester groups in different saponins and sapogenins (saponins of Styrax officinalis L, glycyrrhizin, digitonin) regarding their hemolytic activity. In addition, the aim of this study was to understand which part of the saponin is responsible for the hemolytic activity. The results suggest the aglycone as a trigger of the hemolytic activity because all sapogenins had high hemolytic activity. High hemolytic activity was observed in the case of ester groups in the aglycone part because saponifaction leads to the abolishing of the hemolytic activity, while esterification of carboxyl groups seems to enhance the hemolytic activity. In further studies, Segal et al. [104] modified different steroid sapogenins (hecogenin-a, kryptogenin-a) and a triterpene sapogenin (glycyrrhetinic acid) to investigate the influence of ester groups on hemolytic activity. A comparison was made between esterified sapogenins containing additional polar groups and sapogenins containing ester groups. The polar groups of some sapogenins have been esterified with bifunctional acids bearing two polar groups (i.e., dicarboxylic acid, hydroxy acid), resulting in an ester function containing carboxylic acid or hydroxyl groups. In some cases, the polar group of the ester function was removed by acetylation or methylation. These model sapogenins were compared with those containing a simple ester group. Based on the results, sapogenins with an ester function bearing an additional polar group showed less hemolytic activity compared with those having a simple ester. By acetylation or
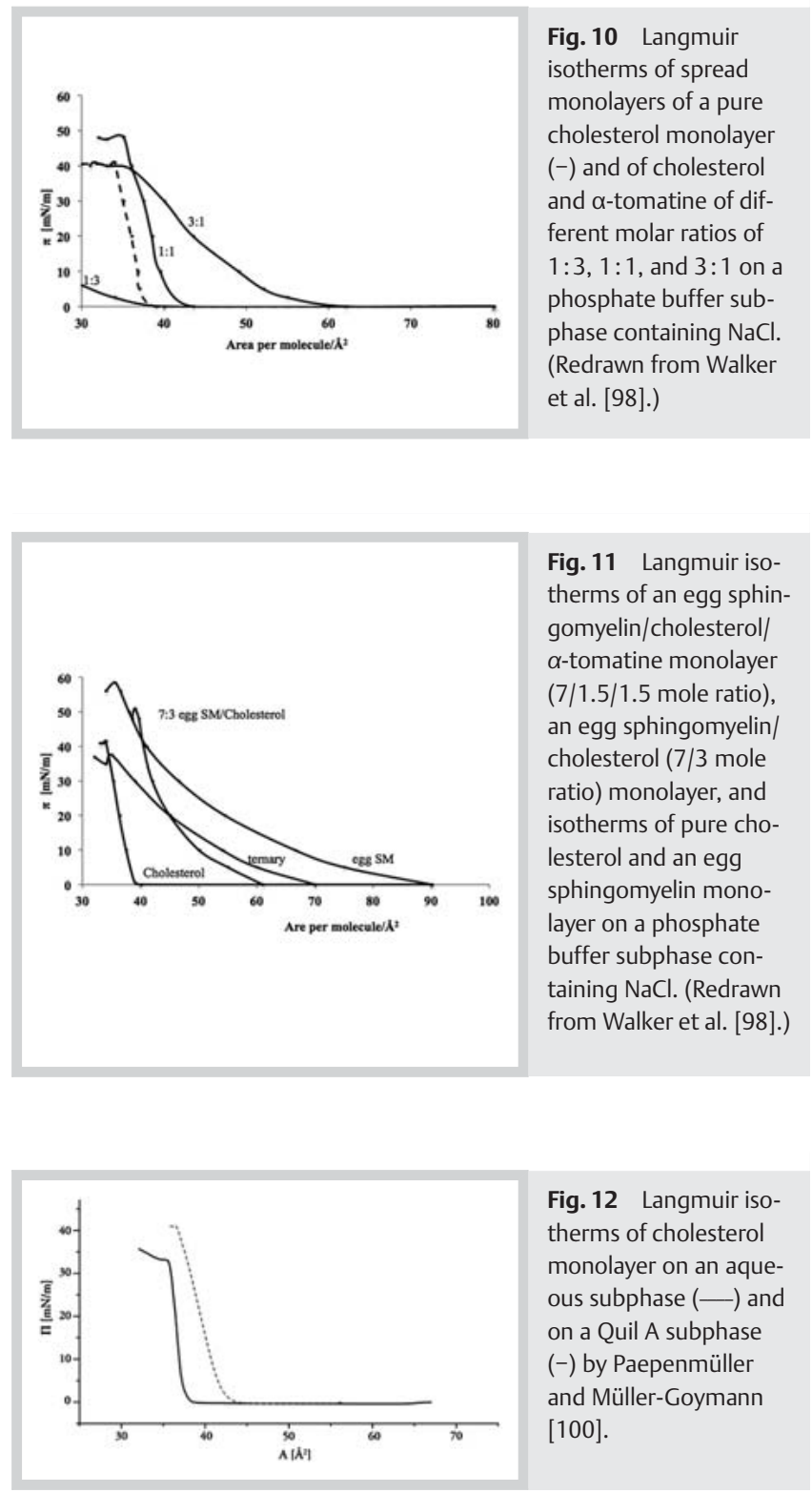

methylation of the polar groups in the ester function, hemolytic activity increased. The authors assumed that not the integration of ester groups enhances hemolytic activity but removal of the polar group of the sapogenin. Another finding was that neither a hydroxyl group nor an ester group at C-3 is essential for the hemolysis. Furthermore, in the case of sapogenins with two polar groups, i.e., glycyrrhetinic acid, esterfication of one polar group enhances hemolytic activitiy in contrast to esterfication of both polar groups, whereas it is less important which polar group is modified. Therefore, the monoesters seem to be more active than the diesters.

In a subsequent contribution, Segal et al. [105] studied the influence of sugar moieties in saponins (digitonin, solanine, tomatine, glycyrrhizin, glycyrrhetinic acid) in terms of hemolytic activity and confirmed their previous results that the aglycone part is crucial for hemolytic activity. From these results, they suggested a two-step process of hemolysis. In the first step, the saponin is bound to the erythrocytes and in the second step, hydrolysis occurs which results in the hemolytic activity of the aglycone. Before hemolysis is accomplished, hydrolysis of the saponin by 
appropiate membrane glycosidase is likely to occur. Therefore, hydrolysis of the glycosidic bond seems to be a requirement for hemolytic activity. Reasons of low hemolytic activity of saponins might be a reduced adsorption to the erythrocyte membranes or a low enzyme activity, which is important for hydrolysis. Akiyama et al. [76] also suggested that the aglycone part is crucial for interactions with cholesterol. Therefore, the attachment of saponins to the erythrocyte membrane occurs mainly due to the cholesterol content in the membrane. Because of the hypothesis from Segal et al. [105], it could be speculated that the differences in hemolytic activity of the two saponins of ivy (hederin, hederacoside C) occur due to a different number of sugar chains. The second sugar chain of hederacoside $C$ could prevent the binding to the erythrocyte membrane, or hydrolysis of glycosidic bound by glykosidase is not complete.

Schlösser and Wulff [106] studied the hemolytic activity of monodesmosidic triterpene saponins and their aglycones and found the presence of polar groups in ring A and moderate polar groups in rings $\mathrm{E}$ and $\mathrm{D}$ to be important. Sapogenins containing $16 \alpha-\mathrm{OH}$ or 16 -keto in connection with $3 \beta-\mathrm{OH}$ exhibit very high hemolytic activity. They asserted that the presence of $3 \beta-\mathrm{OH}$ is essential for hemolytic activity, which is in contradiction to statements of Segal et al. [104]. The type of saponins and number (monodesmosidic, bidesmosidic) of sugar chains also affect the hemolytic activity. An indication of the influence of sugar chains is given by saponins from ivy. $\alpha$-Hederin exhibits much higher activity compared to hederacoside C. $\alpha$-Hederin and hederacoside $C$ have the same aglycone but a different number of sugar chains (2 versus 5 ).

By binding of the polar groups (e.g., sugar chains) in rings $\mathrm{D} / \mathrm{E}$ in addition to ring A, hemolytic activity decreases drastically. This is particularly evident with regard to a second sugar chain in bidesmosidic saponin hederacoside $\mathrm{C}$ that looses hemolytic activity. A further saponin with low toxicity is the triterpene saponin glycyrrhizin and its aglycone glycyrrhetininc acid. Both compounds exhibit low membrane toxicity ( Table 2 ), which is possibly associated with polar moieties linked to rings A, C, and E. The aglycone carries a carboxy group (ring $\mathrm{E}$ ), an additional keto group ( ring $\mathrm{C}$ ), and a hydroxyl group (ring A), which is linked to the sugar in the saponin. Furthermore, esterification of a carboxyl group leads to an increase in hemolytic activity, which was also described by Segal et al. $[78,106]$. Together with the results from Langmuir film balance studies described before, a relationship between membrane toxicity and hemolytic activity of saponins from the Hedera genus may be drawn. As described by Böttger et al. [82], $\alpha$-hederin exhibits high membrane toxicity and a high potential in the reduction of surface pressure due to its amphiphilic character. It also has high hemolytic activity. In contrast, hederacoside $C$ has no hemolytic activity and less toxicity [82]. Due to structural similarities between $\alpha$-hederin and hederacoside $C$, the second sugar chain seems to have a strong impact on the loss of hemolytic activity in the case of hederacoside $C$.

Nakamura et al. [107] investigated the hemolytic activity of saponins on human erythrocytes and the extent of liposome-damaging activities. They assigned a strong interaction of saponins with erythrocytes to a high affinity to cholesterol. Saponins with hemolytic activity also cause permeabilization of liposomes, but only of liposomes that contain cholesterol. A correlation between hemolytic activity and affinity to cholesterol was observed for digitonin and hederacoside $C$. Digitonin exhibits a high affinity to cholesterol and high membrane toxicity ( Table 2). In model membrane systems, digitonin forms complexes with cholesterol,
Table 3 Ingredients of different negative chargely lipid nanoparticles: Egg-PC = L- $\alpha$-phosphatidylcholine from egg yolk, MPL = monophosphoryl lipid A (adjuvant activity), peptide = ovalbumin antigen peptide.

\begin{tabular}{|lll|}
\hline Liposomes/transferosomes & Ethosomes & Cubosomes \\
\hline Egg-PC & Egg-PC & Phytantriol \\
\hline Polysorbate 80 & Ethanol & Poloxamer 407 \\
\hline (MPL) & (MPL) & (MPL) \\
\hline Peptide & Peptide & \\
\hline (Quil A) & (Quil A) & Quil A \\
\hline
\end{tabular}

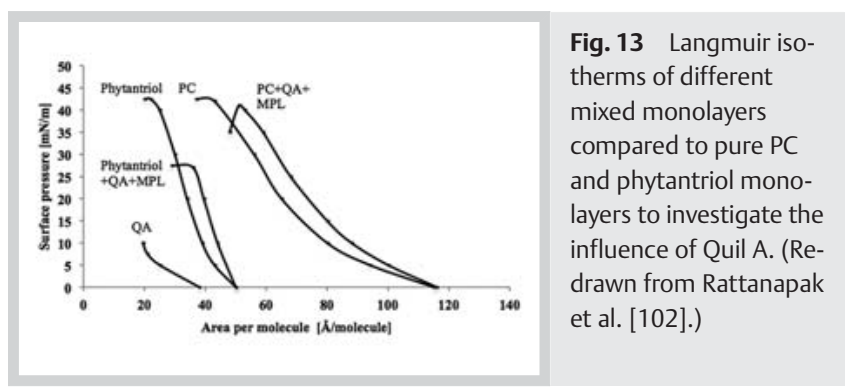

which leads to a destruction of the membrane. This correlates with a high hemolytic activity of digitonin. In contrast, hederacoside $\mathrm{C}$ has a low affinity for cholesterol ( Fig. 6), which is associated with a low hemolytic activity. As mentioned earlier, saponins with two sugar chains exhibit no hemolytic properties and thus no permeabilizing effects on liposomes with cholesterol. As Langmuir film balance experiments revealed cholesterol as an important target for saponins in terms of influencing model membrane systems, cholesterol likewise plays a major role in the attack of saponins on erythrocytes. However, Segal and Milo-Goldzweig [108] did not consider cholesterol as an essential binding partner for hemolytically active saponins despite its effect on the hemolytic activity of saponins and sapogenins.

The correlation between adjuvant properties and hemolytic activity of 47 saponins was tested by Oda et al. [109]. No correlation between adjuvant and hemolytic activity was observed. Some saponins exhibit strong adjuvant and hemolytic activity, whereas other saponins exert either strong hemolytic or strong adjuvant together with either low adjuvant or low hemolytic activity, respectively. Saponins with adjuvant property and missing hemolytic activity are promising candidates for the development of adjuvanted vaccines.

Votquenne et al. [8] investigated 59 triterpene saponins in terms of the relationship between structure and hemolytic activity. Hemolysis tests showed higher hemolytic activity of monodesmosidic saponins compared to bidesmosidic saponins, which is in agreement with Nakamura et al. [107] and Hase et al. [110]. Woldemichael and Wink [111] arrived at the same conclusion for triterpene saponins from $C$. quinoa, that monodesmosidic saponins have higher hemolytic activity than bidesmosidic saponins. Hemolytic activity of monodesmosidic saponins increases with the presence of an osidic residue at position 3 , or with a $16 \alpha-\mathrm{OH}$ group, which is consistent with the report of Schlösser and Wulff [106]. Again, the number of sugar moieties affects the hemolytic activity. Hemolytic activity increases with number of sugar moieties in position 3. Digitonin, a monodesmosidic saponin, is linked with a branched sugar chain consisting of five sugar moieties. This branched sugar chain is also able to stabilize the 


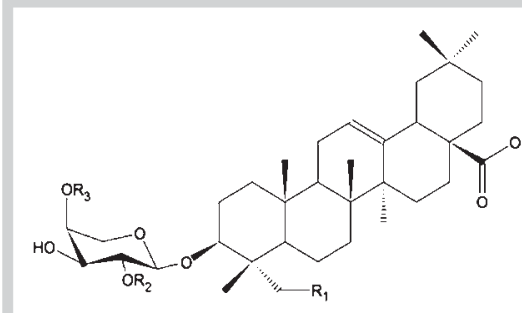

\begin{tabular}{|c|c|c|c|}
\hline Compound & $\mathbf{R}_{1}$ & $\mathrm{R}_{2}$ & $\mathbf{R}_{3}$ \\
\hline$\delta$-hederin & $\mathrm{OH}$ & H & $\mathrm{H}$ \\
\hline$\alpha$-hederin & $\mathrm{OH}$ & $\alpha$-L-Rhap & $\mathrm{H}$ \\
\hline$\beta$-hederin & $\mathrm{H}$ & $\alpha$-L-Rhap & H \\
\hline hederacolchiside A & $\mathrm{OH}$ & $\boldsymbol{\alpha}$-L-Rhap & $\beta$-Glep \\
\hline hederacolchiside $\mathrm{A}_{1}$ & $\mathrm{H}$ & $a$-L-Rhap & $\beta-G l c p$ \\
\hline
\end{tabular}

Fig. 14 Chemical structure of oleanane-type saponins from species of the Hedera genus. (Redrawn from Gauthier et al. [112].)

saponin/cholesterol complex (Akiyama et al. [76]), which could be a reason for hemolytic activity. In contrast, the aglycone of hederacoside $C$ is linked with two sugar moieties, therefore, hederacoside $C$ exhibits very low hemolytic activity, because in bidesmosidic saponins, a polar balance between two sugar chains at posititons 3 and 28 is important for the regulation of hemolytic activity as well as the sugar type [8].

Wang et al. [84] investigated 63 steroid saponins with diosgenin and congeners as aglycone regarding their hemolytic and cytotoxic activity. Diosgenin was connected to various numbers of sugar moeities at position 3. Some new insights about the influence of certain structural features on hemolytic activity were found. The hemolysis tests showed that the number of sugar moieties as well as the sugar linkage influences the hemolytic activity. The hemolytic activity decreases as follows: trisaccharides > disaccharides $>$ monosaccharides. Furthermore, substituents or hydroxyl groups in sugar moieties, e.g., by acetylation, result in a change of hemolytic activity. In some cases, hemolytic activity decreases by substitution of hydroxyl groups, while in other cases activity is less affected. Changes in saponin structure, both in sugar moieties and aglycone, result in an altered hemolytic activity. Based on the results of the hemolytic $\left(\mathrm{HD}_{50}\right)$ and cytotoxic $\left(\mathrm{IC}_{50}\right)$ activity, another important conclusion was drawn in terms of no correlation between these activities.

Gauthier et al. [112] compared hemolytic activity, cytotoxicity, and cell membrane permeabilization of triterpene saponins of lupane and oleanane type with variations in aglycone structure, substituents, and sugar moeities. The difference between lupane and oleanane type involves the annulated ring $\mathrm{E}$. The lupane type consists of four annulated six-membered rings and one annulated five-membered ring, while the oleanane type consists of five annulated six-membered rings.

Different oleanane-type saponins from species of the Hedera genus ( $\alpha$-hederin, $\beta$-hederin, $\delta$-hederin, hederacolchiside $\mathrm{A}$, hederacolchiside $A_{1}$, etc.) were compared to lupane-type saponins and triterpene aglycones ( Fig. 14). A much higher hemolytic activity of oleanane-type saponins was observed. Up to a concentration of $100 \mu \mathrm{M}$, virtually no hemolytic activitiy of lupane-type saponins and the respective aglycones was detected.

The highest hemolytic activity was found for $\beta$-hederin and hederacolchiside $A_{1}$, i.e., saponins without any polar group in ring A. Hederacolchiside $A$, representing the oleanane-type saponin hederagenin with a $\beta$-D-glucopyranose moiety, exhibits higher hemolytic activity than the oleanane-type saponins $\delta$-hederin and $\alpha$-hederin. Interestingly, such saponins show antiproliferative activity against carcinoma and normal skin fibroblasts of human cell lines in vitro. It appears that hemolytic activity of oleanane-type saponins correlates with cytotoxicity. The strongest cytotoxic activity was observed for $\beta$-hederin and hederacolchiside $A_{1}$, likewise the hemolytic activity. The other saponins from species of the Hedera genus ( $\delta$-hederin, $\alpha$-hederin, hederacolchiside $A$, hederagenin saponin) are moderately active. For lupane- type saponins, this correlation was not observed. The results of cell membrane permeabilization assays correlate with results from hemolytic assays for both oleanane- and lupane-type saponins. Lupane-type saponins without hemolytic activity did not permeabilize membranes of carcinoma cells or normal skin fibroblasts at the maximum concentration studied $\left(\mathrm{HD}_{50}>200 \mu \mathrm{M}\right)$. For oleanane-type saponins, high permeabilization activity was observed that correlates with high/moderate hemolytic and cytotoxic activity. $\beta$-Hederin and hederacolchiside $A_{1}$, which have the strongest hemolytic and cytotoxic activity, also show the highest activity of permeabilizing cell membranes. All in all, Gauthier et al. [112] showed that both the hemolytic and cytotoxic activity as well as the cell membrane permeabilization properties depend on structure and type of substituents of the aglycone and of the sugar side chains. With regard to the different oleanane-type saponins from species of the Hedera genus, $\beta$-hederin and hederacolchiside $A_{1}$ with oleanolic acid as the aglycone exhibit the strongest cytotoxic activity compared to the other oleanane-type saponins ( $\delta$-hederin, $\alpha$-hederin, hederacolchiside A, hederagenin saponin) with hederagenin as the aglycone. The difference between these two aglycones is a single polar group $-\mathrm{CH}_{2}-\mathrm{OH}$ at $\mathrm{C}-4$ in ring $\mathrm{A}$. The results are in accordance with the results from Barthomeuf et al. [113]. In general, the hemolytic activity of oleanane-type saponins seems to be correlated with cytotoxicity and thus is a crucial challenge in the development of anticancer agents, because saponins with both anticancer and hemolytic activity are undesirable. Only 2 out of 35 tested saponins belonging to lupane-type saponins exhibited antiproliferative activity without hemolytic activity. They appear to be promising candidates for the development of anticancer agents.

The influence of saponins as a trigger of eryptosis (suicidal death of erythrocytes) was studied by Bissinger et al. [114]. The authors recently reported that erythrocytes might prevent hemolysis by inducing eryptosis, which results in cell shrinkage and cell membrane scrambling, with evidence of phosphatidylserine abundance at the erythrocyte surface. Eryptosis is triggered by increased $\mathrm{Ca}^{2+}$ activity in the cytosol. Activity of $\mathrm{Ca}^{2+}$ as well as extent of phosphatidylserine on erythrocyte surface are important markers for eryptosis.

\section{Immunostimulating Complexes}

$\nabla$

The ISCOMs are particular delivery systems consisting of cholesterol, phospholipid, saponins, and an immunizing antigen (amphiphatic protein) [115]. The most commonly used saponin Quil A is extracted from the bark of $Q$. saponaria Molina [116]. These particular delivery systems exhibit great potential in the development of vaccines due to the adjuvant activity of the Quil A saponin $[117,118]$. Therefore, they are used as antigen carriers, e.g., for subunit vaccines with low immunogenicity [119]. In comparison to common vaccines, a 10 -fold higher immune response is 
achieved with ISCOM-bound antigens [120]. Another important advantage is that they promote both the humoral and the cellular immune response [121]. A variety of antigens have already been tested in ISCOMs in animals [122]. The hemolytic activity of Quil $A$ is a drawback and limits the use for human vaccines. As a plant extract, Quil A consists of different saponins. The content depends on the source and kind of purification method. QS 21 extracted from $Q$. saponaria Molina and purified to a higher extent compared to Quil A exhibits less toxicity [123], which is promising for the development of human ISCOM vaccines [124].

Besides ISCOM, the term ISCOM matrix is also used. While ISCOM consists of cholesterol, phospholipid, Quil A, and a corresponding antigen, the ISCOM matrix represents an ISCOM without any antigen. Essentially, it exhibits the same structure like ISCOM [72]. A prerequisite of ISCOM formation is the interaction between cholesterol and Quil A [125]. Although interaction studies between saponins and cholesterol in biological membranes go back to the ' $60 \mathrm{~s}$ of the 20th century $[126,127]$, they are still being studied to date as outlined above.

Being aware of the interaction between Quil A and cholesterol/ phospholipids is of major importance for understanding ISCOM matrix structure, which was first described in 1984 by Morein et al. [116]. The ISCOM matrix is a cage-like structure with a diameter of approximately $35 \mathrm{~nm}$ consisting of ring-like subunits of about $12 \mathrm{~nm}$. The binding of antigens (virus membrane proteins) on Quil A is due to hydrophobic interactions of Quil A micelles, which are formed above the critical micellar concentration of $0.03 \%$. Therefore, micellar formation appears to be an important prerequisite of ISCOM formation. Structure properties were investigated by TEM (transmission electron microscopy), a widely used method for elucidation of ISCOM structures, but also by cryo transmission electron microscopy and atomic force microscopy $[128,129]$. Other methods for structure elucidation have also been used, such as DLS, to obtain information about particle size and particle size distribution [128].

Özel et al. [130] investigated structural details with TEM of stained and dried ISCOMs ( $\odot$ Fig. 15). ISCOMs were prepared with different proteins (HIV- 1 , hepatitis B, rabies virus) by the dialysis method. They consist of Quil A, cholesterol, and the correspondent antigen, but without any phospholipid. The morphology is similar to the ISCOM matrix without any proteins. Consequently, the morphology is irrespective of the included antigen. Because of a hydrophobic interaction between cholesterol and Quil A, cage-like structures were formed exhibiting icosahedral symmetry. An icosahedron is a polyhedron composed of 20 triangular faces, 30 edges, and 12 vertices. Further experiments revealed the composition of 20 ring-like morphological subunits with an outer diameter of about $15 \mathrm{~nm}$ and an inner open diameter of about $7 \mathrm{~nm}$. These subunits were associated in a pentagonal dodecahedron with a hole on each of the 12 pentagonal faces. A dodecahedron is a polyhedron of 12 pentagons, 20 vertices, and 30 edges.

Kersten et al. [124] described ISCOMs as vesicular structures with a hydrophobic core composed of micelles interacting due to hydrophobic forces, electrostatic repulsion, steric factors, and possibly hydrogen bonds ( Fig. 16). These rigid spherical structures indicate small intrusions on their surface, as visible by freezefracture electron microscopy. The hydrophobic parts of the constituents are inside, providing a hydrophobic core, and the more hydrophilic parts are facing outside. Another important feature is the negatively charged surface of ISCOMs at neutral $\mathrm{pH}$, which is related to glucuronic acid and limits aggregation. Protonation re-
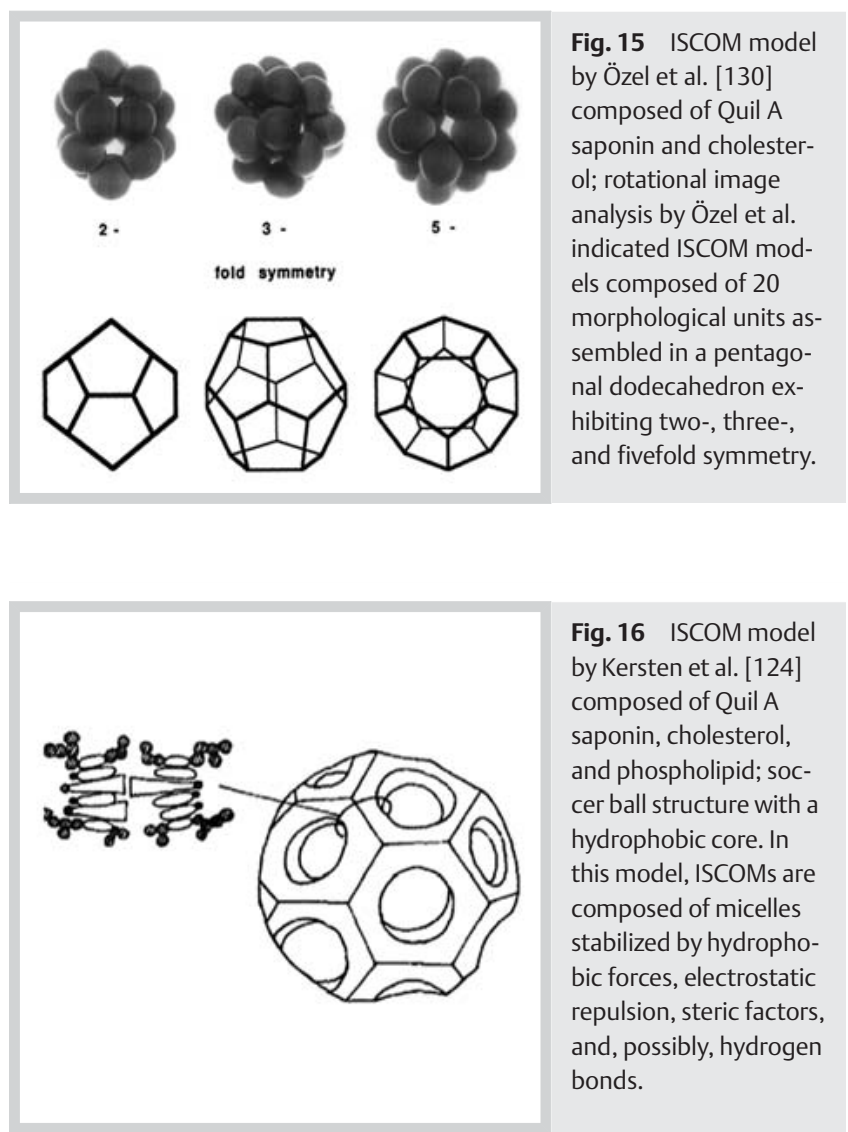

sults in a reversible aggregation. Kersten et al. [124] described an optimal ratio of cholesterol, phospholipid, and Quil A $(1: 1: 4)$ to gain mainly ISCOM particles in contrast to other colloidal particles such as large lamellae or helices. In contrast to Özel et al. [130], the addition of a phospholipid, like phosphatidylethanolamine, seems to have an influence for ISCOM formation. Phospholipids increase the hydrophobicity and are crucial in the presence of Quil A-cholesterol micelles for transition into spherical strucures. Without any phospholipids, flat lamellae will be formed. Likewise, de Vries and other research groups [131,132] observed the requirement of both cholesterol and phospholipid for ISCOM formation.

Demana et al. [133] produced aequeous mixtures of Quil A, cholesterol, and phosphatidylcholine in different ratios by a lipid film hydration method. Negative staining transmission electron microscopy and polarized light microscopy were used to characterize the structures. Depending on the mass ratio of the three components, different colloidal particles resulted, such as ISCOM matrices, liposomes, ring-like micelles, and worm-like micelles. In pseudo-binary systems (Quil A and cholesterol), worm-like micelles were observed. Consequently, an interaction between these components was suggested.

In pseudo-binary systems consisting of Quil A and phosphatidylcholine, layered structures with a predominant lipid part were observed. Quil A appears to form layered structures with phosphatidylcholine, resulting in bilayer structures but not vesicles. In pseudo-ternary systems (Quil A, cholesterol, and phosphatidylcholine), colloidal structures result depending on the mass ratio. ISCOM matrices form in systems with $40-70 \%$ phosphatidylcholine, 20-40\% Quil A, and 10-30\% cholesterol. The authors $[133,134]$ also reported that the use of phosphatidylcholine in- 
stead of phosphatidylethanolamine results in the formation of a more heterogeneous ISCOM population and ISCOM structures with a lower density. Different phospholipids may lead to various interactions, which need to be examined more closely. Generally, the addition of at least $30 \%$ of a phosphoplipid such as phosphatidylcholine is a prerequisite for the formation of ISCOM matrices. Besides cryo-transmission electron micropgraphs of spherical cage-like structures with holes perforating the surface in the range of 40-60 nm, Pedersen et al. [128] characterized ISCOM structures by small-angle X-ray scattering (SAXS) as a new method in this field ( $\odot$ Fig. 17). In agreement with TEM and cryo-TEM observations [135], similar structures were visualized by SAXS with a newly developed and implemented data analysis by Pedersen et al. [128]. Icosahedral structures with holes at the 12 corners were found. These structures may be compared to those ones described by Özel et al. [130]. In accordance with Kersten et al. [124], the hydrophilic parts of the lipid and the sugar parts of Quil A are facing the surface. Furthermore, football-like structures in terms of a dodecahedron consisting of 12 pentagons and 20 hexagons and tennis ball structures consisting of 12 pentagons and 8 hexagons were formed. The tennis ball structures were observed mostly. Many parameters were determined using the SAXS method: outer diameter, thickness, radius, mass fraction, and relative polydispersity. Further experiments were conducted with tetanus toxoid. The morphology and dimension of the structures were comparable to those without any toxoid. Again, the tennis ball structure was found the most. As SAXS gives a look into the inside of the ISCOM structure, a single toxoid was identified within the icosahedral and the tennis ball-like ISCOMs attaching the membrane. In contrast, the football structure is able to enclose two toxoid molecules. Pedersen et al. [128] considerably contributed to the structural elucidation of ISCOMs.

In the case of antigens, they either have to be attached to the ISCOM matrix for an immune response or may be coadministered with ISCOM matrices. Since the addition of phospholipids during ISCOM preparation results in a hydrophobic core [124], the antigens have to be hydrophobic or amphiphilic, which enables the interaction with ISCOM matrices [125]. Hydrophilic antigens need to be modified, for example, by attaching fatty acids or partial denaturation at a low $\mathrm{pH}[136,137]$. As an alternative, the incorporation of cationic molecules provides electrostatic interactions to negatively charged ISCOM matrices [138]. On the other hand, negatively charged molecules are difficult to incorporate. Lendemans et al. [139] produced cationic ISCOMs with a cationic cholesterol derivative. ISCOM-like particles with cage-like morphology and a positive charge were observed beside other colloidal structures. Compared to conventional ISCOMs, the same diameter of $40 \mathrm{~nm}$ was observed. These structures have great potential as delivery systems for proteins and DNA subunit vaccines. Different methods are described by many research groups to observe the morphological structures of ISCOMS by TEM, cryoTEM, and SAXS as well as DLS for the determination of particle size and surface charge (ZP).

As described in the first section, Langmuir film balance studies have proved to be effective for in vitro interaction studies, giving deeper insight into saponin impact on model membrane systems. Cholesterol is suggested to be an important interaction partner of saponins, both in ISCOMs, in model membranes, and erythrocytes. ISCOM formation was only observed in ternary systems (cholesterol, phospholipid, Quil A). Possibly other promising saponins possess the ability to form ISCOMs in ternary systems.

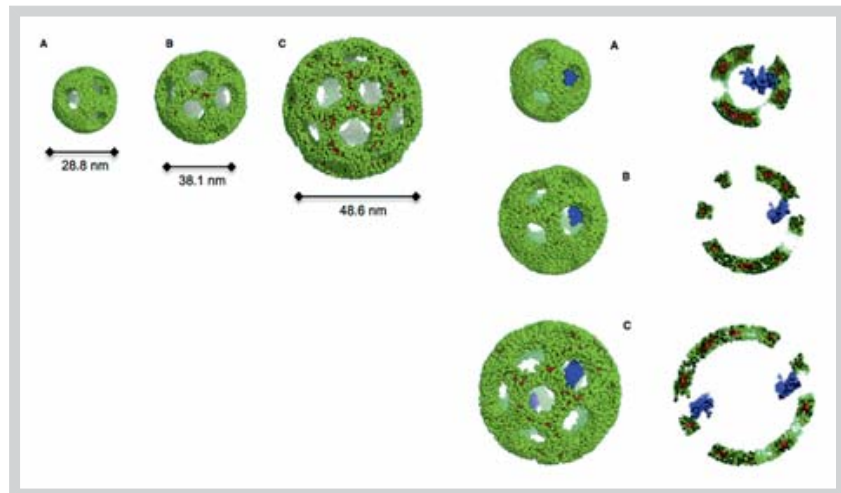

Fig. 17 Suggested ISCOM models from SAXS by Pedersen et al. [128]. Polydisperse distribution of perforated bilayer vesicles with icosahedral, football, and mainly tennis ball structures; $\mathbf{A}$ icosahedral structure, $\mathbf{B}$ tennis ball structure, $\mathbf{C}$ football-like structure. The most common structure is the tennis ball structure composed of 12 pentagons and 8 hexagons with an outer diameter of approx. $40 \mathrm{~nm}$; location of the tetanus toxoid attached to the inner membrane. (Color figure available online only.)

A high affinity for cholesterol was found among others for the monodesmosidic steroid saponin digitonin, for the monodesmosidic triterpene saponin $\alpha$-tomatine, and for the monodesmosidic triterpene saponin $\alpha$-hederin. However, a high affinity for cholesterol seems to promote the hemolytic acitivity of saponins. This is a limiting factor for the development of vaccines with saponins as adjuvants. The saponins listed in this review differ both structurally and in terms of their toxicity. The results suggest a correlation between the hemolytic activity, the affinity for cholesterol, the extent of membrane permeabilization, and the cytotoxicity. The focus should be placed mainly on the sugar chains and the aglycones of the respective saponins. Digitonin, which is connected with a long branched sugar chain, has shown a rather high membrane toxicity and general cytotoxicity. Moreover, digitonin appears to have high hemolytic activity and a high affinity for cholesterol, which results in the formation of digitonin/cholesterol complexes. According to Nakamura et al. [107], high hemolytic activity depends on a high affinity to cholesterol. Furthermore, according to Votquenne et al. [8], monodesmosidic saponins are more hemolytically active ( $\alpha$-hederin, hederacoside $\mathrm{C}$ ) than bidesmosidic saponins. This presumption also applies to digitonin. It has been found that the number of sugar moieties has an effect on the hemolytic activity of monodesmosidic saponins: an increasing number results in an increased hemolytic activity. Transferred to the saponins, digitonin should have the greatest hemolytic activity followed by $\alpha$-tomatine and $\alpha$-hederin.

\section{Conclusion \\ $\nabla$}

Finding the balance between hemolytic activity as a major drawback of quite a number of saponins and the desired pharmacological effect is a crucial prerequisite in drug development. For this purpose, Langmuir trough experiments on a spread monolayer have proven to be a versatile tool to sensitively detect interactions at the molecular level, although a closer look into chemical bonds involved is not possible. To get detailed insight, further methods are necessary.

A promising candidate with regard to fairly low hemolytic activity and a high adjuvant effect in subunit vaccines is the triterpene 
Quil A/QS 21 from the bark of Q. saponaria Molina. As particulate drug delivery systems, ISCOMs appear to be promising for the future. Further saponins such as the steroid saponin $\alpha$-tomatine are also in the focus of interest due to low toxicity. Based on the literature, it is hypothesized that further saponins are able to interact with cholesterol forming drug delivery systems. Therefore, interaction studies of other saponins and saponins' ability to produce drug delivery systems attract high interest.

\section{Conflict of Interest}

The authors declare no conflict of interest.

\section{References}

1 Riguera $R$. Isolating bioactive compounds from marine organisms. J Mar Biotechnol 1997; 5: 187-193

2 Vincken JP, Heng L, de Groot A, Gruppen H. Saponins, classification and occurrence in the plant kingdom. Phytochemistry 2007; 68: 275-297

3 Sparg SG, Light ME, van Staden J. Biological activities and distribution of plant saponins. J Ethnopharmacol 2004; 94: 219-243

4 Podolak I, Galanty A, Sobolewska D. Saponins as cytotoxic agents: a review. Phytochem Rev 2010; 9: 425-474

5 Netala VR, Ghosh SB, Bobbu P, Anitha D, Tartte V. Triterpenoid saponins: a review on biosynthesis, applications and mechanism of their action. Int J Pharm Pharm Sci 2015; 7: 24-28

6 Francis G, Kerem Z, Makkar HP, Becker K. The biological action of saponins in animal systems: a review. Br J Nutr 2002; 88: 587-605

7 Oleszek W, Hamed A. Saponin-based Surfactants. In: Kjellin M, Johansson I, eds. Surfactants from renewable Resources. Chichester, UK: Wiley \& Sons; 2010

8 Voutquenne L, Lavaud C, Massiot G, Men-Olivier LL. Structure-activity relationships of haemolytic saponins. Pharm Biol 2002; 40: 253-262

9 Man S, Gao W, Zhang Y, Huang L, Liu C. Chemical study and medical application of saponins as anti-cancer agents. Fitoterapia 2010; 81: 703-714

10 Waller GR, Yamasaki K. Saponins used in Food and Agriculture. Advances in experimental Medicine and Biology. New York: Springer: 1996

11 Choi YH, Kinghorn AD, Shi X, Zhang H, Teo BK. Abrusoside A: a new type of highly sweet triterpene glycoside. J Chem Soc 1989: 887-888

12 Kim YS, Cho IH, Jeong MJ, Jeong SJ, Nah SY, Cho YS, Kim SH, Go A, Kim SE, Kang SS, Moon CJ, Kim JC, Kim SH, Bae CS. Therapeutic effect of total ginseng saponin on skin wound healing. J Ginseng Res 2011; 35: 360-367

13 Kimura Y, Sumiyoshi M, Kawahira K, Sakanaka M. Effects of ginseng saponins isolated from Red Ginseng roots on burn wound healing in mice. Br J Pharmacol 2006; 148: 860-870

14 Simões CMO, Amoros M, Girre L. Mechanism of antiviral activity of triterpenoid saponins. Phytother Res 1999; 13: 323-328

15 Amoros M, Fauconnier B, Girre RL. In vitro antiviral activity of a saponin from Anagallis arvensis, Primulaceae, against herpes simplex virus and poliovirus. Antiviral Res 1987; 8: 13-25

16 Gosse B, Gnabre J, Bates RB, Dicus CW, Nakkiew P, Huang RCC. Antiviral saponins from Tieghemella heckelii. J Nat Prod 2002; 65: 1942-1944

17 Yang XW, Zhao J, Cui YX, Liu XH, Ma CM, Hattori M, Zhang LH. AntiHIV-1 protease triterpenoid saponins from the seeds of Aesculus chinensis. J Nat Prod 1999; 62: 1510-1513

18 Shao Y, Chin CK, Ho CT, Ma W, Garrison SA, Huang MT. Anti-tumor activity of the crude saponins obtained from Asparagus. Cancer Lett 1996; 104: 31-36

19 Mimaki Y, Kuroda M, Ide A, Kameyama A, Yokosuka A, Sashida Y. Steroidal saponins from the aerial parts of Dracaena draco and their cytostatic activity on HL-60 cells. Phytochemistry 1999; 50: 805-813

20 Mimaki Y, Kuroda M, Kameyama A, Yokosuka A, Sashida Y. Steroidal saponins from the underground parts of Ruscus aculeatus and their cytostatic activity on HL-60 cells. Phytochemistry 1998; 48: 485-493

21 Mimaki Y, Kuroda M, Kameyama A, Yokosuka A, Sashida Y. Steroidal saponins from the rhizomes of Hosta sieboldii and their cytostatic activity on HL-60 cells. Phytochemistry 1998; 48: 1361-1369

22 Mimaki Y, Kuroda M, Asano T, Sashida Y. Triterpene saponins and lignans from the roots of Pulsatilla chinensis and their cytotoxic activity against HL-60 cells. J Nat Prod 1999; 62: 1279-1283
23 Liu WK, Xu SX, Che CT. Anti-proliferative effect of ginseng saponins on human prostate cancer cell line. Life Sci 2000; 67: 1297-1306

24 Dong $M$, Feng XZ, Wang BX, Wu LJ, Ikejima T. Two novel furostanol saponins from the rhizomes of Dioscorea panthaica Prain et Burkill and their cytotoxic activity. Tetrahedron 2001; 57: 501-506

25 Dong $M$, Feng XZ, Wu LJ, Wang BX, Ikejima T. Two new steroidal saponins from the rhizomes of Dioscorea panthaica and their cytotoxic activity. Planta Med 2001; 67: 853-857

26 Fattorusso E, Lanzotti V, Taglialatela-Scafati O, Di Rosa M, Ianaro A. Cytotoxic saponins from bulbs of Allium porrum L. J Agric Food Chem 2000; 48: 3455-3462

27 Weng A, Thakur M, von Mallinckrodt B, Beceren-Braun F, Gilabert-Oriol F, Wiesner B, Eichhorst J, Böttger S, Melzig MF, Fuchs H. Saponins modulate the intracellular trafficking of protein toxins. J Control Release 2012; 164: 74-86

28 Lee Y, Jung JC, Ali Z, Khan IA, Oh S. Anti-inflammatory effect of triterpene saponins isolated from Blue Cohosh (Caulophyllum thalictroides). Evid Based Complement Alternat Med 2012; 2012: 798192

29 Yao Y, Yang X, Shi Z, Ren G. Anti-inflammatory activity of saponins from Quinoa (Chenopodium quinoa Willd.) seeds in lipopolysaccharide-stimulated RAW 264.7 macrophages cells. J Food Sci 2014; 79: 1018-1023

30 Xin W, Zhang L, Sun F, Jiang N, Fan H, Wang T, Li Z, He J, Fu F. Escin exerts synergistic anti-inflammatory effects with low doses of glucocorticoids in vivo and in vitro. Phytomedicine 2011; 18: 272-277

31 Kwak WJ, Han CK, Chang HW, Kim HP, Kang SS, Son KH. Loniceroside C, an antiinflammatory saponin from Lonicera japonica. Chem Pharm Bull (Tokyo) 2003; 51: 333-335

32 Just MJ, Recio MC, Giner RM, Cuéllar MJ, Máñez S, Bilia AR, Ríos JL. Antiinflammatory activity of unusual lupane saponins from Bupleurum fruticescens. Planta Med 1998; 64: 404-407

33 Tapondjou LA, Ponou KB, Teponno RB, Mbiantcha M, Djoukeng JD, Nguelefack TB, Watcho P, Cadenas AG, Park HJ. In vivo anti-inflammatory effect of a new steroidal saponin, mannioside $A$, and its derivatives isolated from Dracaena mannii. Articles Drug Efficacy And Safety 2008; 31: 653-658

34 Avato P, Bucci R, Tava A, Vitali C, Rosato A, Bialy Z, Jurzysta M. Antimicrobial activity of saponins from Medicago sp.: structure-activity relationship. Phytother Res 2006; 20: 454-457

35 Khanna VG, Kannabiran K. Antimicrobial activity of saponin fractions of the leaves of Gymnema sylvestre and Eclipta prostrata. World J Microbiol Biotechnol 2008; 24: 2737-2740

36 Soetan KO, Oyekunle MA, Aiyelaagbe OO, Fafunso MA. Evaluation of the antimicrobial activity of saponins extract of Sorghum Bicolor L. Moench. Afr J Biotechnol 2006; 5: 2405-2407

37 Sharma A, Sati SC, Sati OP, Sati MD, Kothiyal SK, Semwal DK, Mehta A. A new triterpenoid saponin and antimicrobial activity of ethanolic extract from Sapindus mukorossi Gaertn. J Chem 2013; 1-5

38 Teshima Y, Ikeda T, Imada K, Sasaki K, El-Sayed MA, Shigyo M, Tanaka S, Ito $S$. Identification and biological activity of antifungal saponins from shallot (Allium cepa L. Aggregatum group). J Agric Food Chem 2013; 61: 7440-7445

39 Zamilpa A, Tortoriello J, Navarro V, Delgado G, Alvarez L. Five new steroidal saponins from Solanum chrysotrichum leaves and their antimycotic activity. J Nat Prod 2002; 65: 1815-1819

40 Escalante AM, Santecchia CB, López SN, Gattuso MA, Gutiérrez Ravelo A, Delle Monache F, Gonzalez Sierra M, Zacchino SA. Isolation of antifungal saponins from Phytolacca tetramera, an Argentinean species in critic risk. J Ethnopharmacol 2002; 82: 29-34

41 De Lucca AJ, Bland JM, Vigo CB, Cushion M, Selitrennikoff CP, Peter J, Walsh TJ. CAY-I, a fungicidal saponin from Capsicum sp. fruit. Med Mycol 2002; 40: 131-137

42 Rajput ZI, Hu SH, Xiao CW, Arijo AG. Adjuvant effects of saponins on animal immune responses. J Zhejiang Univ Sci B 2007; 8: 153-161

43 Marty-Roix R, Vladimer GI, Pouliot K, Weng D, Buglione-Corbett R, West $K$, MacMicking JD, Chee JD, Wang S, Lu S, Lien E. Identification of QS-21 as an inflammasome-activating molecular component of saponin adjuvants. J Biol Chem 2015; 291: 1123-1136

44 Soltysik S, Wu JY, Recchia J, Wheeler DA, Newman MJ, Coughlin RT, Kensil $C R$. Structure/function studies of QS-21 adjuvant: assessment of triterpene aldehyde and glucuronic acid roles in adjuvant function. Vaccine 1995; 13: 1403-1410

45 Kensil CR, Kammer R. QS-21: a water-soluble triterpene glycoside adjuvant. Expert Opin Investig Drugs 1998; 7: 1475-1482

46 Silveira F, Cibulski SP, Varela AP, Marqués JM, Chabalgoity A, de Costa F Yendo AC, Gosmann G, Roehe PM, Fernández C, Ferreira F. Quillaja brasi- 
liensis saponins are less toxic than Quil A and have similar properties when used as an adjuvant for a viral antigen preparation. Vaccine 2011; 29: 9177-9182

47 Fleck JD, Kauffmann C, Spilki F, Lencina CL, Roehe PM, Gosmann G. Adjuvant activity of Quillaja brasiliensis saponins on the immune responses to bovine herpesvirus type 1 in mice. Vaccine 2006; 24: 7129-7134

48 Cibulski SP, Silveira F, Mourglia-Ettlin G, Teixeira TF, dos Santos HF, Yendo AC, de Costa F, Fett-Neto AG, Gosmann G, Roehe PM. Quillaja brasiliensis saponins induce robust humoral and cellular responses in a bovine viral diarrhea virus vaccine in mice. Comp Immunol Microbiol Infect Dis 2016; 45: 1-8

49 Cibulski SP, Mourglia-Ettlin G, Teixeira TF, Quirici L, Roehe PM, Ferreira F, Silveira F. Novel ISCOMs from Quillaja brasiliensis saponins induce mucosal and systemic antibody production, T-cell responses and improved antigen uptake. Vaccine 2016; 34: 1162-1171

50 Gilabert-Oriol R, Mergel K, Thakur M, von Mallinckrodt B, Melzig MF, Fuchs $H$, Weng A. Real-time analysis of membrane permeabilizing effects of oleanane saponins. Bioorg Med Chem 2013; 21: 2387-2395

51 Rajananthanan P, Attard GS, Sheikh NA, Morrow WJW. Evaluation of novel aggregate structures as adjuvants: composition, toxicity studies and humoral responses. Vaccine 1999; 17: 715-730

52 Sheikh NA, Rajananthanan P, Attard GS, Morrow WJW. Generation of antigen specific CD8+ cytotoxic T cells following immunization with soluble protein formulated with novel glycoside adjuvants. Vaccine 1999; 17: 2974-2982

53 Tomsik P, Micuda S, Sucha L, Cermakova E, Suba P, Zivny P, Mazurova Y, Knizek J, Niang $M$, Rezacova $M$. The anticancer activity of alpha-tomatine against mammary adenocarcinoma in mice. Biomed Pap Med Fac Univ Palacky Olomouc Czech Repub 2013; 157: 153-161

54 Friedman M, Levin CE, Lee SU, Kim HJ, Lee IS, Byun JO, Kozukue N. Tomatine-containing green tomato extracts inhibit growth of human breast, colon, liver, and stomach cancer cells. J Agric Food Chem 2009; 57: 5727-5733

55 Zhao B, Zhou B, Bao L, Yang Y, Guo K. Alpha-tomatine exhibits antiinflammatory activity in lipopolysaccharide-activated macrophages. Inflammation 2015; 38: 1769-1776

56 Trute A, Gross J, Mutschler E, Nahrstedt A. In vitro antispasmodic compounds of the dry extract obtained from Hedera helix. Planta Med 1997; 63: 125-129

57 Favel A, Steininetz MD, Regli P, Vidal-Olivier E, Elias R, Balansard G. In vitro antifungal activity of triterpenoid saponins. Planta Med 1994; 60: 50-53

58 Ridoux O, Di Giorgio C, Delmas F, Elias R, Mshvildadze V, Dekanosidze G, Kemertelidze E, Balansard G, Timon-David P. In vitro antileishmanial activity of three saponins isolated from ivy, alpha-hederin, beta-hederin and hederacolchiside $A(1)$, in association with pentamidine and amphotericin B. Phytother Res 2001; 15: 298-301

59 Delmas F, Di Giorgio C, Elias R, Gasquet M, Azas N, Mshvildadze V, Dekanosidze G, Kemertelidze E, Timon-David P. Antileishmanial activity of three saponins isolated from ivy, alpha-hederin, beta-hederin and hederacolchiside A1, as compared to their action on mammalian cells cultured in vitro. Planta Med 2000; 66: 343-347

60 Kim JM, Yoon JN, Jung JW, Choi HD, Shin YJ, Han CK, Lee HS, Kang HE. Pharmacokinetics of hederacoside $C$, an active ingredient in AG NPP709, in rats. Xenobiotica 2013; 43: 985-992

61 Van Rossum TG, Vulto AG, de Man RA, Brouwer JT, Schalm SW. Review article: glycyrrhizin as a potential treatment for chronic hepatitis $C$. Aliment Pharmacol Ther 1998; 12: 199-205

62 Akamatsu H, Komura J, Asada Y, Niwa Y. Mechanism of anti-inflammatory action of glycyrrhizin: effect on neutrophil functions including reactive oxygen species generation. Planta Med 1991; 57: 119-121

63 Thirugnanam S, Xu L, Ramaswamy K, Gnanasekar M. Glycyrrhizin induces apoptosis in prostate cancer cell lines DU-145 and LNCaP. Oncol Rep 2008; 20: 1387-1392

64 Pompei R, Flore O, Marccialis MA, Pani A, Loddo B. Glycyrrhizic acid inhibits virus growth and inactivates virus particles. Nature 1979; 281 : 689-690

65 Ito M, Sato A, Hirabayashi K, Tanabe F, Shigeta S, Baba M, De Clerca E, Nakashima H, Yamamoto $N$. Mechanism of inhibitory effect of glycyrrhizin on replication of human immunodeficiency virus (HIV). Antiviral Res 1988; 10: 289-298

66 Ashfaq UA, Masoud MS, Nawaz Z, Riazuddin S. Glycyrrhizin as antiviral agent against Hepatitis C Virus. J Transl Med 2011; 9: 1-7
67 Amagaya S, Sugishita E, Ogihara Y, Ogawa S, Okada K, Aizawa T. Comparative studies of the stereoisomers of glycyrrhetinic acid on anti-inflammatory activities. J Pharmacobiodyn 1984; 7: 923-928

68 Hardy ME, Hendricks JM, Paulson JM, Faunce NR. 18 $\beta$-glycyrrhetinic acid inhibits rotavirus replication in culture. Virol J 2012; 9: 1-7

69 Satomi Y, Nishino H, Shibata S. Glycyrrhetinic acid and related compounds induce G1 arrest and apoptosis in human hepatocellular carcinoma HepG2. Anticancer Res 2005; 25: 4043-4048

70 Sharma G, Kar S, Palit S, Das PK. 18 $\beta$-Glycyrrhetinic acid induces apoptosis through modulation of Akt/FOXO3a/Bim pathway in human breast cancer MCF-7 cells. J Cell Physiol 2012; 227: 1923-1931

71 Rönnberg B, Fekadu M, Morein B. Adjuvant activity of non-toxic Quillaja saponaria Molina components for use in ISCOM matrix. Vaccine 1995; 13: 1375-1382

72 Sun HX, Xie Y, Ye YP. Advances in saponin-based adjuvants. Vaccine 2009; 27: 1787-1796

73 Agarwal SK, Rastogi RP. Triterpenoid saponins and their genins. Phytochemistry 1974; 13: 2623-2645

74 Schulman JH, Rideal EK. Molecular interaction in monolayers: I-complexes between large molecules. Proc R Soc Lond B Biol Sci 1937; 122: 29-45

75 Gögelein H, Hüby A. Interaction of saponin and digitonin with black lipid membranes and lipid monolayers. Biochim Biophys Acta 1984; 773 : 32-38

76 Akiyama T, Takagi S, Sankawa U, Inari S, Saito H. Saponin-cholesterol interaction in the multibilayers of egg yolk lecithin as studied by deuterium nuclear magnetic resonance: digitonin and its analogs. Biochemistry 1980; 19: 1904-1911

77 Nishikawa M, Nojima S, Akiyama T, Sankawa U, Inoue K. Interaction of digitonin and its analogs with membrane cholesterol. J Biochem 1984; 96: 1231-1239

78 Segal R, Mansour M, Zaitschek DV. Effect of ester groups on the haemolytic action of some saponins and sapogenins. Biochem Pharmacol 1966; 15: 1411-1416

79 Korchowiec B, Gorczyca M, Wojszko K, Janikowska M, Henry M, Rogalska $E$. mpact of two different saponins on the organization of model lipid membranes. Biochim Biophys Acta 2015; 1848: 1963-1973

$80 \mathrm{Yu} \mathrm{BS}$, Choi HO. The effects of digitonin and glycyrrhizin on liposomes. Arch Pharm Res 1986; 9: 119-125

81 Sudji IR, Subburaj Y, Frenkel N, García-Sáez AJ, Wink M. Membrane disintegration caused by the steroid saponin digitonin is related to the presence of cholesterol. Molecules 2015; 20: 20146-20160

82 Böttger S, Hofmann K, Melzig MF. Saponins can perturb biologic membranes and reduce the surface tension of aqueous solutions: a correlation? Bioorg Med Chem 2012; 20: 2822-2828

83 Böttger S, Melzig MF. The influence of saponins on cell membrane cholesterol. Bioorg Med Chem 2013; 21: 7118-7124

84 Wang Y, Zhang Y, Zhu Z, Zhu S, Li Y, Li M, Yu B. Exploration of the correlation between the structure, hemolytic activity, and cytotoxicity of steroid saponins. Bioorg Med Chem 2007; 15: 2528-2532

85 Keukens EA, de Vrije T, Jansen LA, de Boer H, Janssen M, de Kroon AI, Jongen WM, de Kruijff $B$. Glycoalkaloids selectively permeabilize cholesterol containing biomembranes. Biochim Biophys Acta 1996; 1279: 243250

86 Armah CN, Mackie AR, Roy C, Price K, Osbourn AE, Bowyer P, Ladha S. The membrane-permeabilizing effect of avenacin A-1 involves the reorganization of bilayer cholesterol. Biophys J 1999; 76: 281-290

87 Augustin JM, Kuzina V, Andersen SB, Bak S. Molecular activities, biosynthesis and evolution of triterpenoid saponins. Phytochemistry 2011; 72: 435-457

88 Chwalek M, Lalun N, Bobichon H, Plé K, Voutquenne-Nazabadioko L. Structure-activity relationships of some hederagenin diglycosides: haemolysis, cytotoxicity and apoptosis induction. Biochim Biophys Acta 2006 ; 1760: 1418-1427

89 Wojciechowski K, Orczyk M, Gutberlet T, Geue T. Complexation of phospholipids and cholesterol by triterpenic saponins in bulk and in monolayers. Biochim Biophys Acta 2016; 1858: 363-373

90 Sakamoto S, Nakahara $H$, Uto T, Shoyama $Y$, Shibata O. Investigation of interfacial behavior of glycyrrhizin with a lipid raft model via a Langmuir monolayer study. Biochim Biophys Acta 2013; 1828: 1271-1283

91 Sakamoto S, Uto T, Shoyama Y. Effect of glycyrrhetinic acid on lipid raft model at the air/water interface. Biochim Biophys Acta 2015; 1848 : 434-443 
92 Melzig MF, Bader G, Loose R. Investigations of the mechanism of membrane activity of selected triterpenoid saponins. Planta Med 2001; 67: 43-48

93 Roddick JG, Drysdale RB. Destabilization of liposome membranes by the steroidal glycoalkaloid $\alpha$-tomatine. Phytochemistry 1984; 23 : 543-547

94 Morrow WJW, Yang YW, Sheikh NA. Immunobiology of the tomatine adjuvant. Vaccine 2004; 22: 2380-2384

95 Stine KJ, Hercules RK, Duff JD, Walker BW. Interaction of the glycoalkaloid tomatine with DMPC and sterol monolayers studied by surface pressure measurements and Brewster angle microscopy. J Phys Chem B 2006; 110: 22220-22229

96 Keukens EAJ, de Vrije T, van den Boom C, de Waard P, Plasman HH, Thiel $F$, Chupin V, Jongen WM, de Kruijff B. Molecular basis of glycoalkaloid induced membrane disruption. Biochim Biophys Acta 1995; 1240: 216-228

97 Keukens EAJ, de Vrije T, Fabrie CH, Demel RA, Jongen WMF, de Kruijff B. Dual specificity of sterol-mediated glycoalkaloid induced membrane disruption. Biochim Biophys Acta 1992; 1110: 127-136

98 Walker BW, Manhanke N, Stine KJ. Comparison of the interaction of tomatine with mixed monolayers containing phospholipid, egg sphingomyelin, and sterols. Biochim Biophys Acta 2008; 1778: 2244-2257

99 Ramstedt B, Slotte JP. Interaction of cholesterol with sphingomyelins and acyl-chain-matched phosphatidylcholines: a comparative study of the effect of the chain length. Biophys J 1999; 76: 908-915

100 Paepenmüller T, Müller-Goymann CC. Influence of Quil A on liposomal membranes. Int J Pharm 2014; 475: 138-146

101 Wojciechowski K, Orczyk M, Gutberlet T, Trapp M, Marcinkowski K, Kobiela T, Geue T. Unusual penetration of phospholipid mono- and bilayers by Quillaja bark saponin biosurfactant. Biochim Biophys Acta 2014; 1838: 1931-1940

102 Rattanapak T, Young K, Rades T, Hook S. Comparative study of liposomes, transfersomes, ethosomes and cubosomes for transcutaneous immunisation: characterisation and in vitro skin penetration. J Pharm Pharmacol 2012; 64: 1560-1569

103 Kohli AK, Alpar HO. Potential use of nanoparticles for transcutaneous vaccine delivery: effect of particle size and charge. Int J Pharm 2004; 275: 13-17

104 Segal R, Milo-Goldzweig I, Schupper H, Zaitschek DV. Effect of ester groups on the haemolytic action of sapogenins. II. Esterification with bifunctional acids. Biochem Pharmacol 1970; 19: 2501-2507

105 Segal R, Shatkovsky P, Milo-Goldzweig I. On the mechanism of saponin hemolysis - I. Hydrolysis of the glycosidic bond. Biochem Pharmacol 1974; 23: 973-981

106 Schlösser E, Wulff G. Structural specificity of saponin hemolysis. I. Triterpene saponins and aglycones. Z Naturforsch B 1969; 24: 12841290

107 Nakamura T, Inoue K, Nojima S, Sankawa U, Shoji J, Kawasaki T, Shibata $S$. Interaction of saponins with red blood cells as well as with the phosphatidylcholine liposomal membrane. J Pharmacobiodyn 1979; 2: 374-382

108 Segal R, Milo-Goldzweig I. The susceptibility of cholesterol-depleted erythrocytes to saponin and sapogenin hemolysis. Biochim Biophys Acta 1978; 512: 223-226

109 Oda K, Matsuda H, Murakami T, Katayama S, Ohgitani T, Yoshikawa M. Adjuvant and haemolytic activities of 47 saponins derived from medicinal and food plants. Biol Chem 2000; 381: 67-74

110 Hase J, Kobashi K, Mitsui K, Namba T, Yoshizaki M, Tomimori T. The structure-hemolysis relationship of oleanolic acid derivatives and inhibition of the saponin-induced hemolysis with sapogenins. J Pharmacobiodyn 1981; 4: 833-837

111 Woldemichael GM, Wink M. Identification and biological activities of triterpenoid saponins from Chenopodium quinoa. J Agric Food Chem 2001; 49: 2327-2332

112 Gauthier C, Legault J, Girard-Lalancette K, Mshvildadze V, Pichette A. Haemolytic activity, cytotoxicity and membrane cell permeabilization of semi-synthetic and natural lupane- and oleanane-type saponins. Bioorg Med Chem 2009; 17: 2002-2008

113 Barthomeuf C, Debiton E, Mshvildadze V, Kemertelidze E, Balansard G. In vitro activity of hederacolchisid A1 compared with other saponins from Hedera colchica against proliferation of human carcinoma and melanoma cells. Planta Med 2002; 68: 672-675
114 Bissinger R, Modicano P, Alzoubi K, Honisch S, Faggio C, Abed M, Lang F. Effect of saponin on erythrocytes. Int J Hematol 2014; 100: 51-59

115 Sjölander A, Cox JC, Barr IG. ISCOMs: an adjuvant with multiple functions. J Leukoc Biol 1998; 64: 713-723

116 Morein B, Sundquist B, Höglund S, Dalsgaard K, Osterhaus A. Iscom, a novel structure for antigenic presentation of membrane proteins from enveloped viruses. Nature 1984; 308: 457-460

117 Morein B, Lövgren K, Höglund S, Sundquist B. The ISCOM: an immunostimulating complex. Immunol Today 1987; 8: 333-338

118 Jacobsen NE, Fairbrother WJ, Kensil CR, Lim A, Wheeler DA, Powell MF. Structure of the saponin adjuvant QS-21 and its base-catalyzed isomerization product by $1 \mathrm{H}$ and natural abundance $13 \mathrm{C}$ NMR spectroscopy. Carbohydr Res 1996; 280: 1-14

119 Demana PH, Fehske C, White K, Rades T, Hook S. Effect of incorporation of the adjuvant Quil A on structure and immune stimulatory capacity of liposomes. Immunol Cell Biol 2004; 82: 547-554

120 Morein $B$. The iscom antigen-presenting system. Nature 1988; 332: 287-288

121 Sun HX, Xie Y, Ye YP. ISCOMs and ISCOMATRIXTM. Vaccine 2009; 27: 4388-4401

122 Claassen I, Osterhaus A. The iscom structure as an immune-enhancing moiety: experience with viral systems. Res Immunol 1992; 143: 531541

123 Kensil CR, Wu JY, Soltysik S. Structural and immunological characterization of the vaccine adjuvant QS-21. Vaccine Design 1995; 6: 525541

124 Kersten GFA, Spiekstra A, Beuvery EC, Crommelin DJA. On the structure of immune-stimulating saponin-lipid complexes (iscoms). Biochim Biophys Acta 1991; 1062: 165-171

125 Morein B, Bengtsson KL. Immunomodulation by iscoms, immune stimulating complexes. Methods 1999; 19: 94-102

126 Glauert AM, Dingle JT, Lucy JA. Action of saponin on biological cell membranes. Nature 1962; 196: 952-955

127 Dourmashkin RR, Dougherty RM, Harris RJC. Electron microscopic observations on Rous sarcoma virus and cell membranes. Nature 1962; 194: 1116-1119

128 Pedersen JS, Oliveira CL, Hübschmann HB, Arleth L, Manniche S, Kirkby $N$, Nielsen HM. Structure of immune stimulating complex matrices and immune stimulating complexes in suspension determined by small-angle x-ray scattering. Biophys J 2012; 102: 2372-2380

129 Pearse MJ, Drane D. ISCOMATRIX adjuvant for antigen delivery. Adv Drug Deliv Rev 2005; 57: 465-474

130 Özel M, Höglund S, Gelderblom HR, Morein B. Quaternary structure of the immunostimulating complex (iscom). J Ultrastruct Mol Struct Res 1989; $102: 240-248$

131 De Vries P, Van Wezel AL, Beuvery EC. Process for preparing immunogenic complexes and pharmaceutical composition containing these complexes. US Patent 4900549; 1990

132 Copland MJ, Rades T, Davies NM. Hydration of lipid films with an aqueous solution of Quil A: a simple method for the preparation of immune-stimulating complexes. Int J Pharm 2000; 196: 135-139

133 Demana PH, Davies NM, Vosgerau U, Rades T. Pseudo-ternary phase diagrams of aqueous mixtures of Quil A, cholesterol and phospholipid prepared by the lipid-film hydration method. Int J Pharm 2004; 270 : 229-239

134 Kersten GFA, Crommelin DJA. Liposomes and ISCOMS as vaccine formulations. Biochim Biophys Acta 1995; 1241: 117-138

135 Myschik J, Lendemans DG, McBurney WT, Demana PH, Hook S, Rades T. On the preparation, microscopic investigation and application of ISCOMs. Micron 2006; 37: 724-734

136 Reid G. Soluble proteins incorporate into ISCOMs after covalent attachment of fatty acid. Vaccine 1992; 10: 597-602

137 Morein B, Ekström J, Lövgren K. Increased immunogenicity of a nonamphipathic protein (BSA) after inclusion into iscoms. J Immunol Methods 1990; 128: 177-181

138 Morein B, Hu KF, Abusugra I. Current status and potential application of ISCOMs in veterinary medicine. Adv Drug Deliv Rev 2004; 56: 1367-1382

139 Lendemans DG, Myschik J, Hook S, Rades T. Cationic cage-like complexes formed by DC-cholesterol, Quil-A, and phospholipid. J Pharm Sci 2005; 94: 1794-1807 